\title{
La construcción naval en época romana: el barco de Es Grum de Sal, Conejera (San Antonio de Portmany, Ibiza)
}

\section{The naval construction in Roman times: el boat of Es Grum de Sal, Conejera (San Antonio de Portmany, Ibiza)}

Carlos León Amores ${ }^{1}$

Recibido: 05-05-2018

Aceptado: 24-09-2018

\section{Resumen}

Este artículo presenta el estudio de los restos del casco del mercante romano de Grum de Sal, hundido a 20 metros de profundidad en el islote de Conejera, frente a San Antonio, en Ibiza, cuando transportaba un cargamento de ánforas de salazón Dressel 14 b. El estudio de este naufragio nos muestra elementos del casco tales como la quilla, cuadernas, tracas del forro, puntales y elementos separadores de la carga.

Palabras clave: arqueología submarina, construcción naval, Grum de Sal, mercante romano, ánforas, Dressel 14, islote de Conejera.

\begin{abstract}
This article presents the study of the merchant roman,s hull of Grum de Sal, shipwrecked at twenty meters depth in the Conejera Island, just near San Antonio, Ibiza, when it was shipping with a cargo of Dressel $14 \mathrm{~b}$ salted fish amphoras. This shipwreck shows parts of the hull like the keel, frames, shell, pillars stancious and separators pieces of the cargo.
\end{abstract}

Keywords: underwater archaeology, ship building, Grum de Sal, merchant Roman ship, amphora, Dressel 14, Conejera Island.

\section{Hallazgo E INTERVENCiONES ARQUeOlógicas}

El barco romano de Es Grum de Sal fue descubierto por Benito Vilar-Sancho en 1960. En el verano de ese año localizaron un campo de ánforas en un fondeadero denominado situado en la parte sureste de la isla de Conejera, ubicada frente a la bahía de San Antonio (Vilar-Sancho y Mañá Angulo, 1964: 177). De este hallazgo dieron cuenta al entonces director del Museo Arqueológico de Ibiza, José María Mañá Angulo, al que entregaron tres piezas extraídas del yacimiento. Ese mismo año, un yate inglés, el Pagán II, estuvo realizando prospecciones arqueológicas autorizadas en esta zona localizando, además del campo de ánforas, los restos de madera de un barco romano (Figuras 1 y 2). Un año más tarde, VilarSancho y Mañá Angulo solicitaron permiso de excavación a la Dirección General de Bellas Artes, realizando dos campañas en los años 1962 y 1963, en las que posicionaron el barco, realizaron una primera planimetría de la ensenada y excavaron parte del yacimiento (Vilar-Sancho y Mañá Angulo, 1964: 185) (Figura 3).

En 1982, Ibiza se convierte en un punto de atención de las primeras prospecciones arqueológicas submarinas que están comenzando a llevarse a cabo en España.

\footnotetext{
1 cleonamores@gmail.com
} 

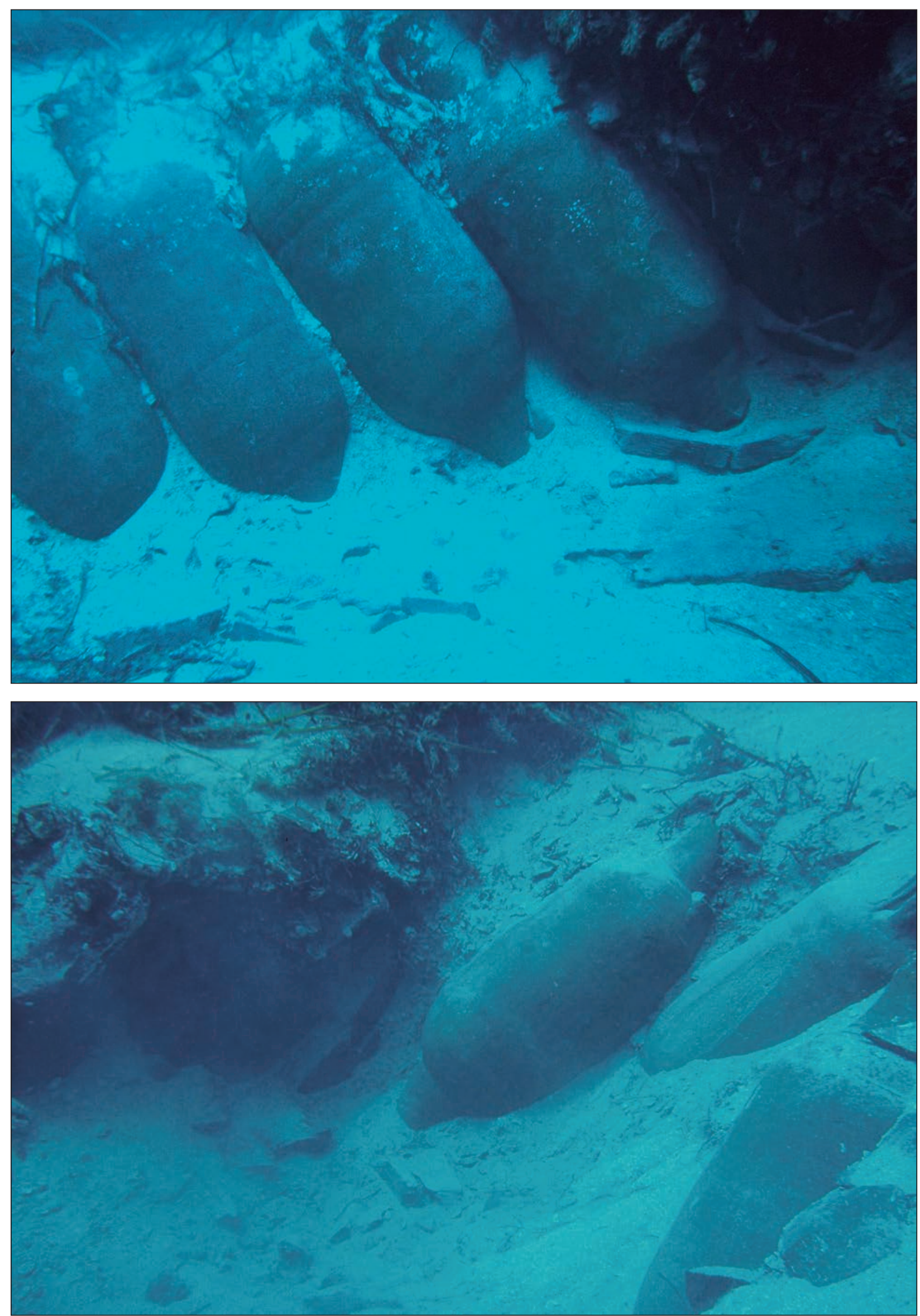

Figura 1 y 2. Restos del naufragio localizados por Vilar-Sancho en 1962 y 1963 (Fotos: Benito Vilar-Sancho). 


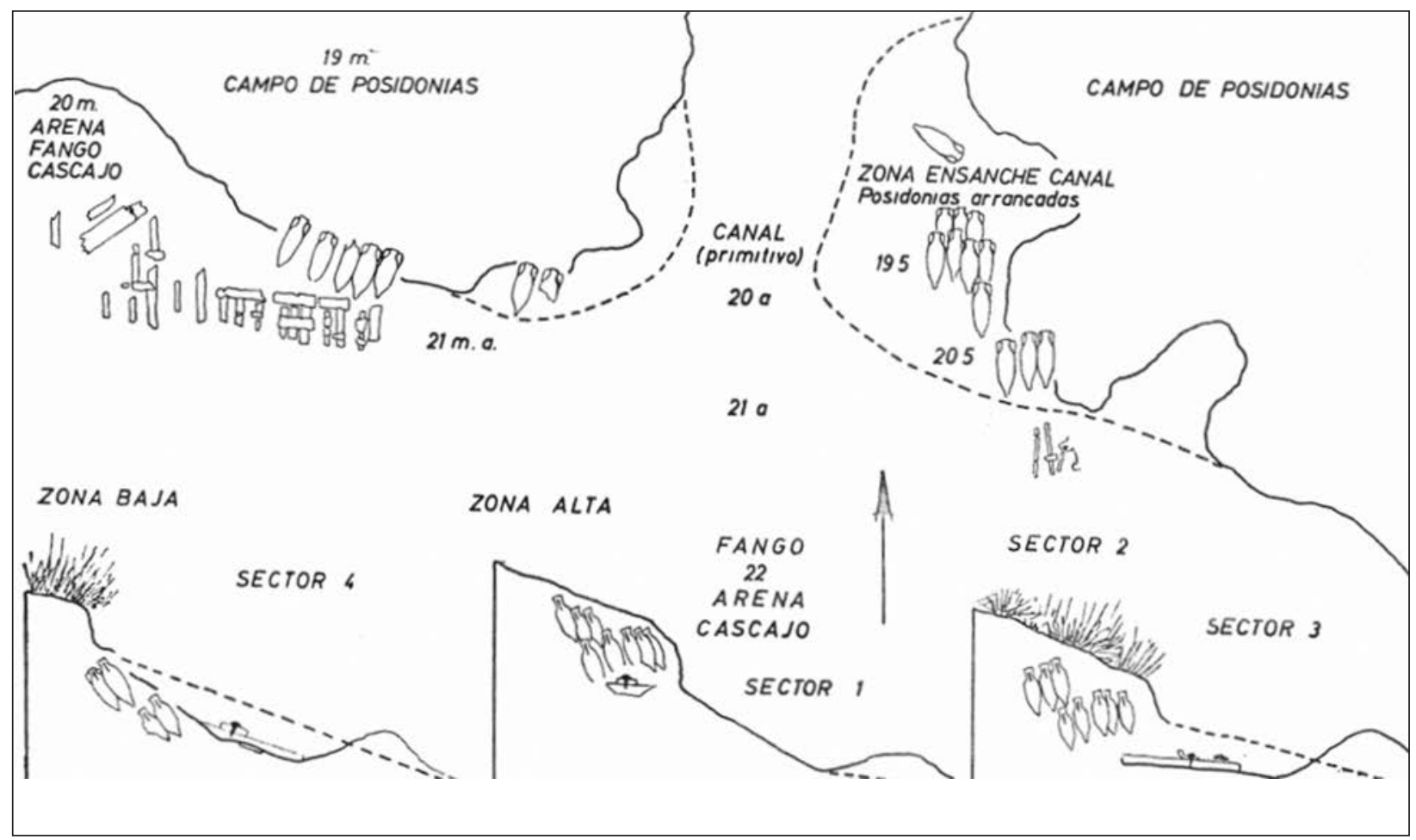

Figura 3. Dibujo de los restos del naufragio según Benito Vilar-Sancho.

El objetivo de las prospecciones en el litoral ibicenco, dirigidas por Belén Martínez y Virginia Galván, era la búsqueda y localización sistemática de todos aquellos restos sumergidos que pudieran dar información sobre el comercio y la navegación antigua, (Galván y Martínez, 1992). Uno de los lugares objeto de estas prospecciones fue la isla de Conejera, y concretamente, el barco de Es Grum de Sal (Figura 4).

Años más tarde, en 1990, tras la firma de un convenio entre el Gobierno Balear y el Ministerio de Cultura, se planteó la continuación de este trabajo, con dos campañas de campo y tres objetivos fundamentales: el estudio batimétrico de la zona, la excavación horizontal del fondeadero, y el estudio y documentación del casco del barco romano para tratar de interpretar la estructura del casco y formular una hipótesis del hundimiento de este mercante (Figuras 5 y 6).

Para documentar el casco de este mercante romano se instaló una cuadrícula de $4 \times 4$ metros con tubos metálicos señalizados cada diez centímetros, con cabos elásticos que formaban una retícula que dividía el espacio en cuadros de $1 \times 1$ metro. Sobre esta estructura se instaló otra superior similar con tubos de pvc con interior de aluminio y sobre ella se montó un puente de aluminio con ruedas y dos cámaras subacuáticas, y un conformador de cuadernas de aluminio con varillas del mismo material de un metro de longitud separadas cada diez centímetros. Los dibujos de detalles del casco se realizaron con una cuadrí- cula móvil de pvc de 1 x 1 reticulada cada diez centímetros que se situaba sobre cada uno de los cuadros de la estructura general (Figuras 7, 8, 9).

El conjunto de elementos del casco del barco se fue limpiando y etiquetando para poder identificar los distintos elementos: transversales, longitudinales y verticales así como elementos sueltos desplazados de la estructura general del casco. Además se señalizaron las clavijas de fijación de las lengüetas y la separación entre las tracas del forro para su mejor visualización en las fotografías (Figura 10). En algunos casos concretos se extrajeron piezas sueltas del casco para su estudio en superficie que, posteriormente, fueron devueltas a su posición original en el yacimiento (Figura 11).

\section{UBICACIÓN Y ESTADO DE CONSERVACIÓN}

Los restos del barco romano descansan en un claro de arena circundado por posidonias con una pendiente de unos 12 grados buzando hacia el Sur. El entorno está compuesto por arenas de tamaño medio (entre 0,5 y 0,25 milímetros) procedentes de la descomposición de las calizas masivas y compactas que forman la costa, y por restos de conchas y esqueletos de pequeños animales marinos (Figura 12).

El casco de este mercante, situado en posición oblicua con respecto a la pendiente, está a unos 20 metros de profundidad en su zona Noreste y a unos 21,4 en su zona Suroeste, lo que supone una pendiente aproximada de unos 9 grados. 


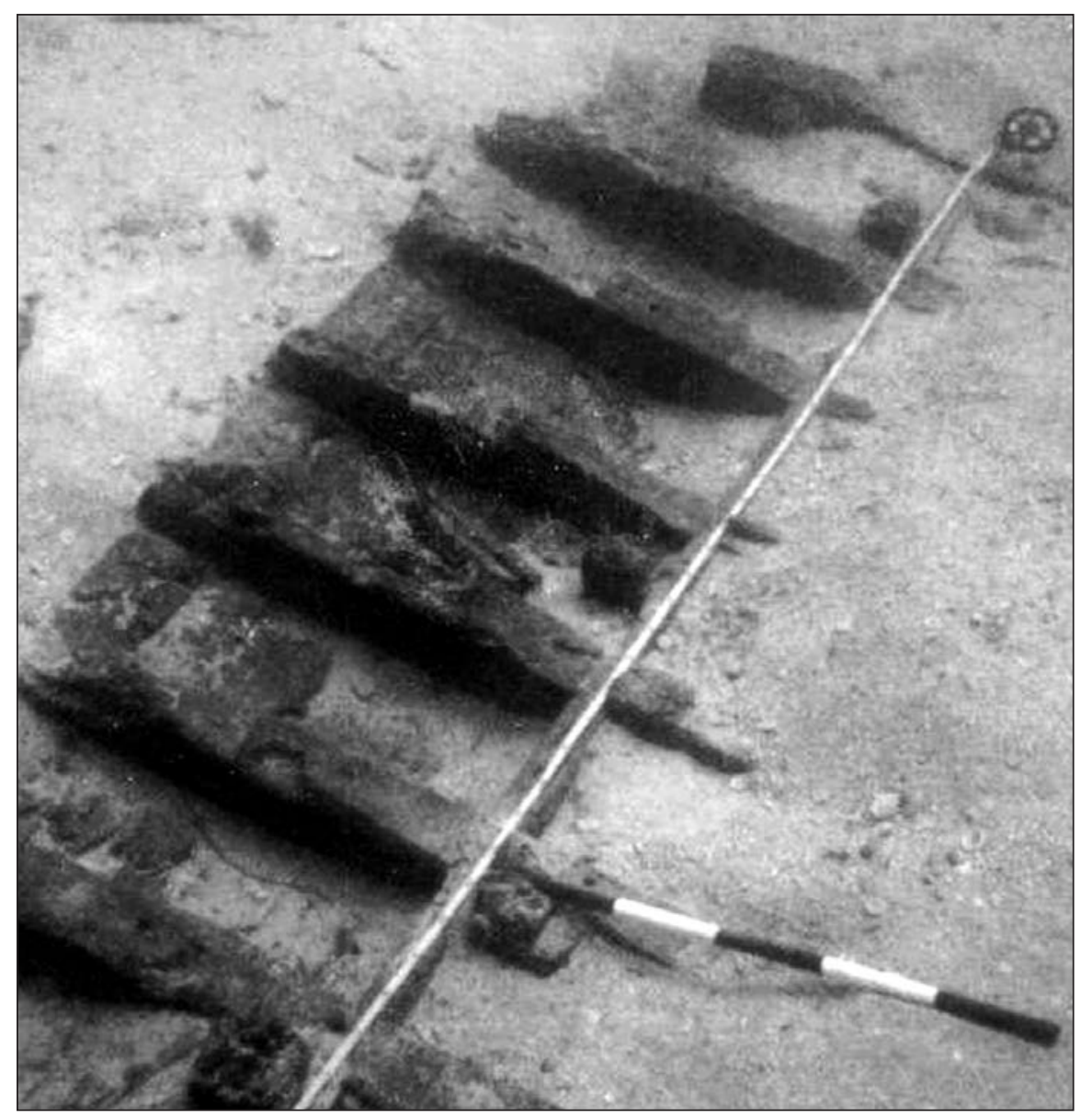

Figura 4. Restos del casco del barco de Grum de Sal fotografiados en 1986 (Foto: Belén Martínez).

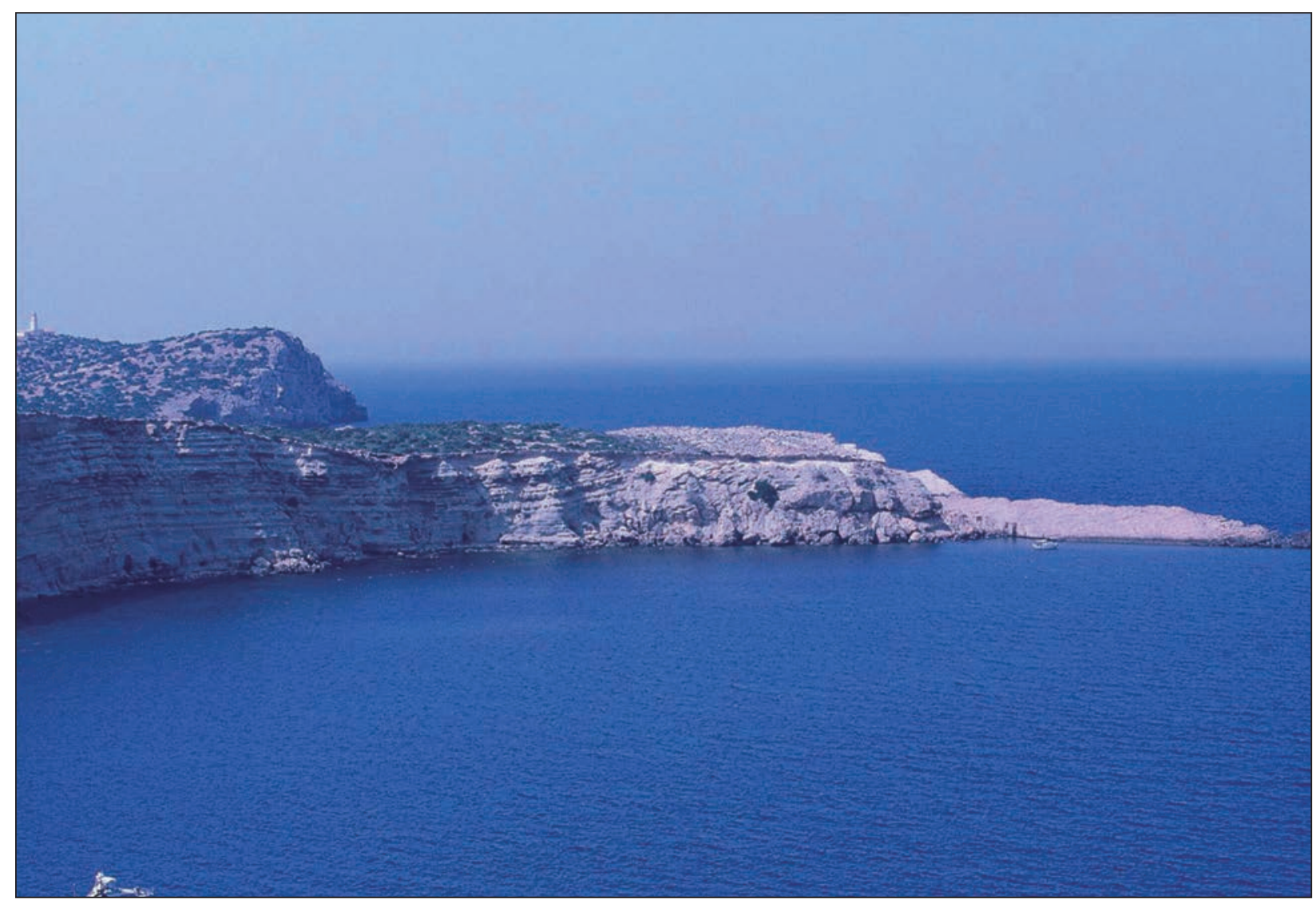

Figura 5. Fondeadero de Es Grum de Sal, Conejera, durante la campaña de investigación de 1991 (Foto: Carlos León). 


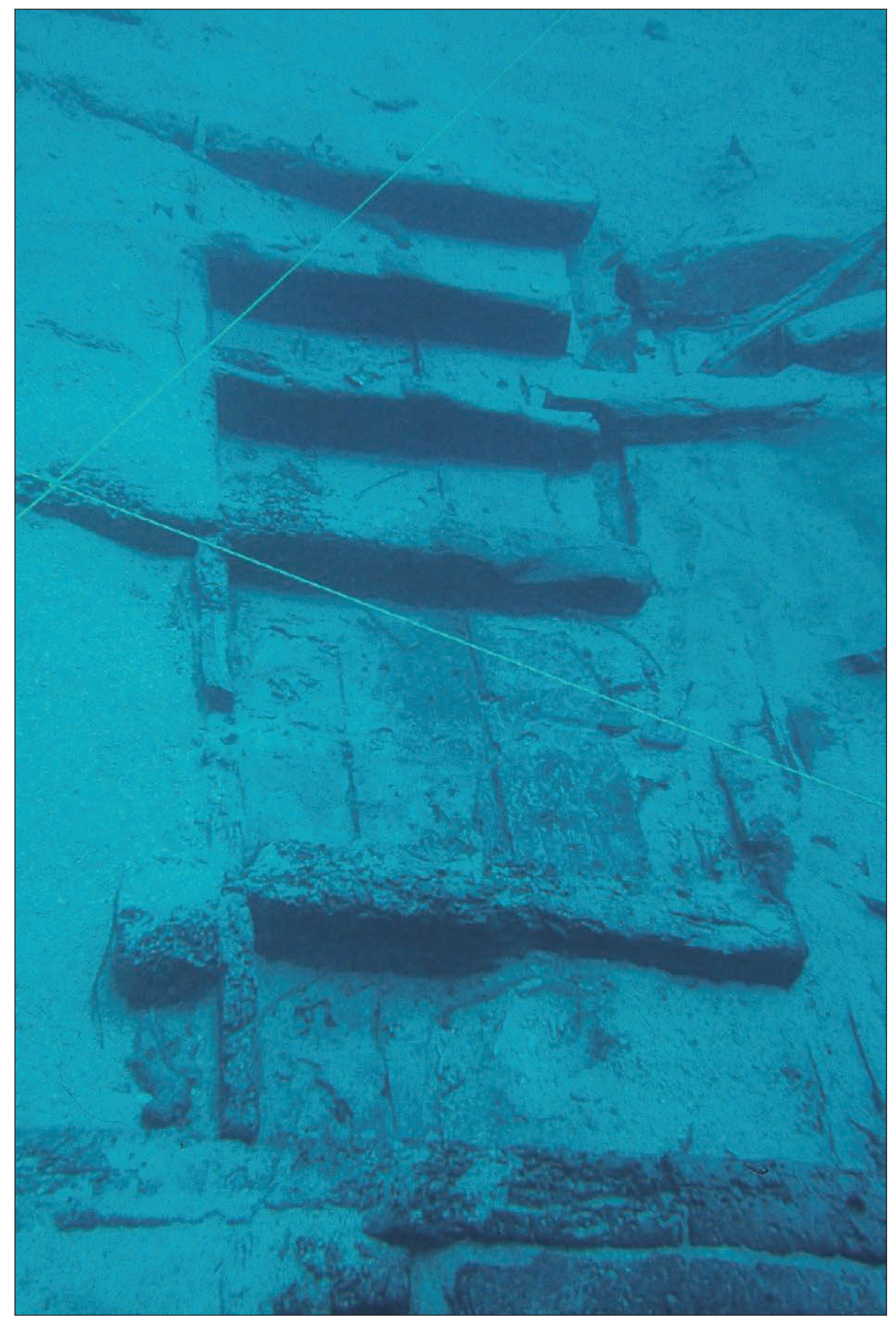

Figura 6. Restos del casco durante el proceso de limpieza en la campaña de 1991 (Foto: José Latova). 


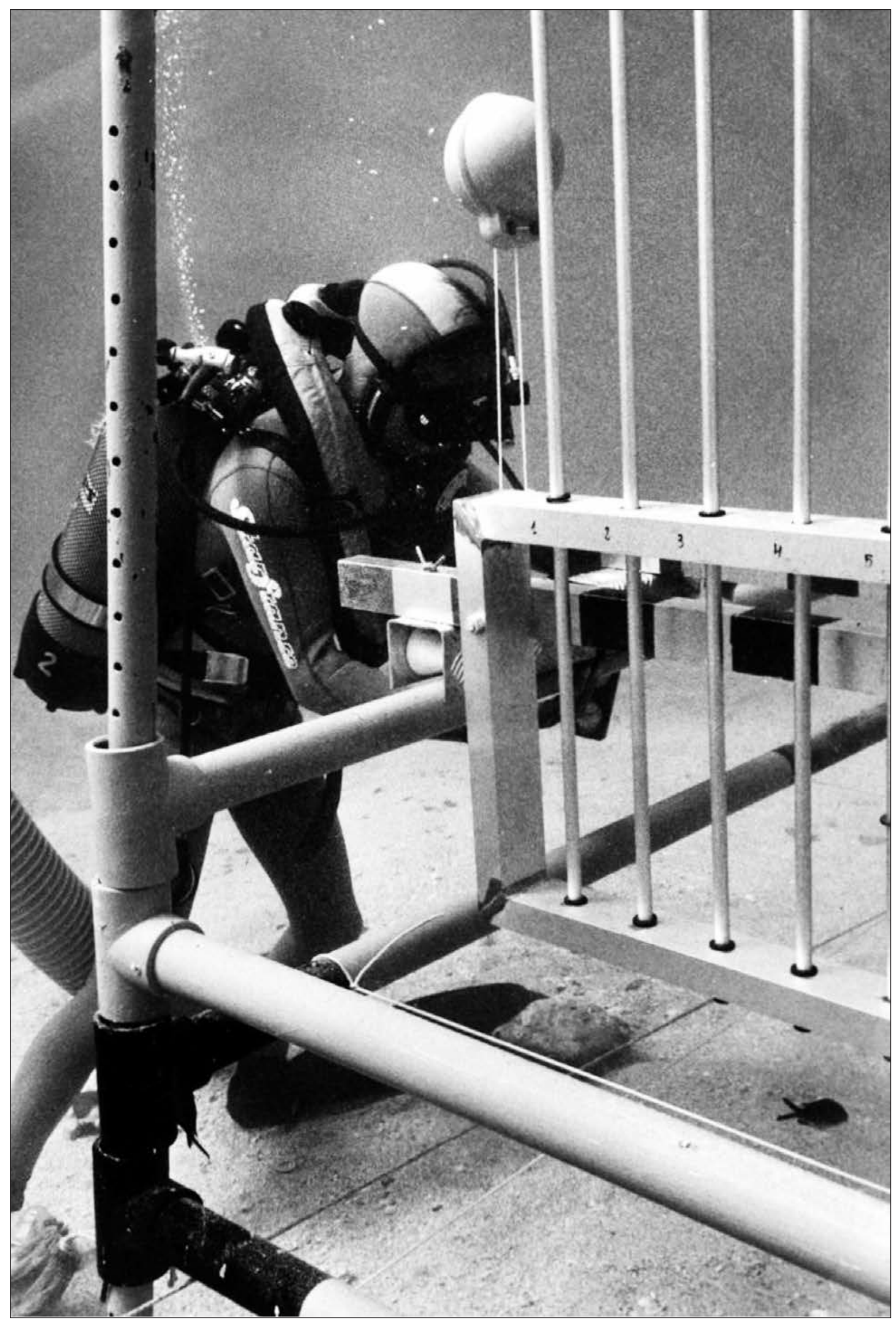



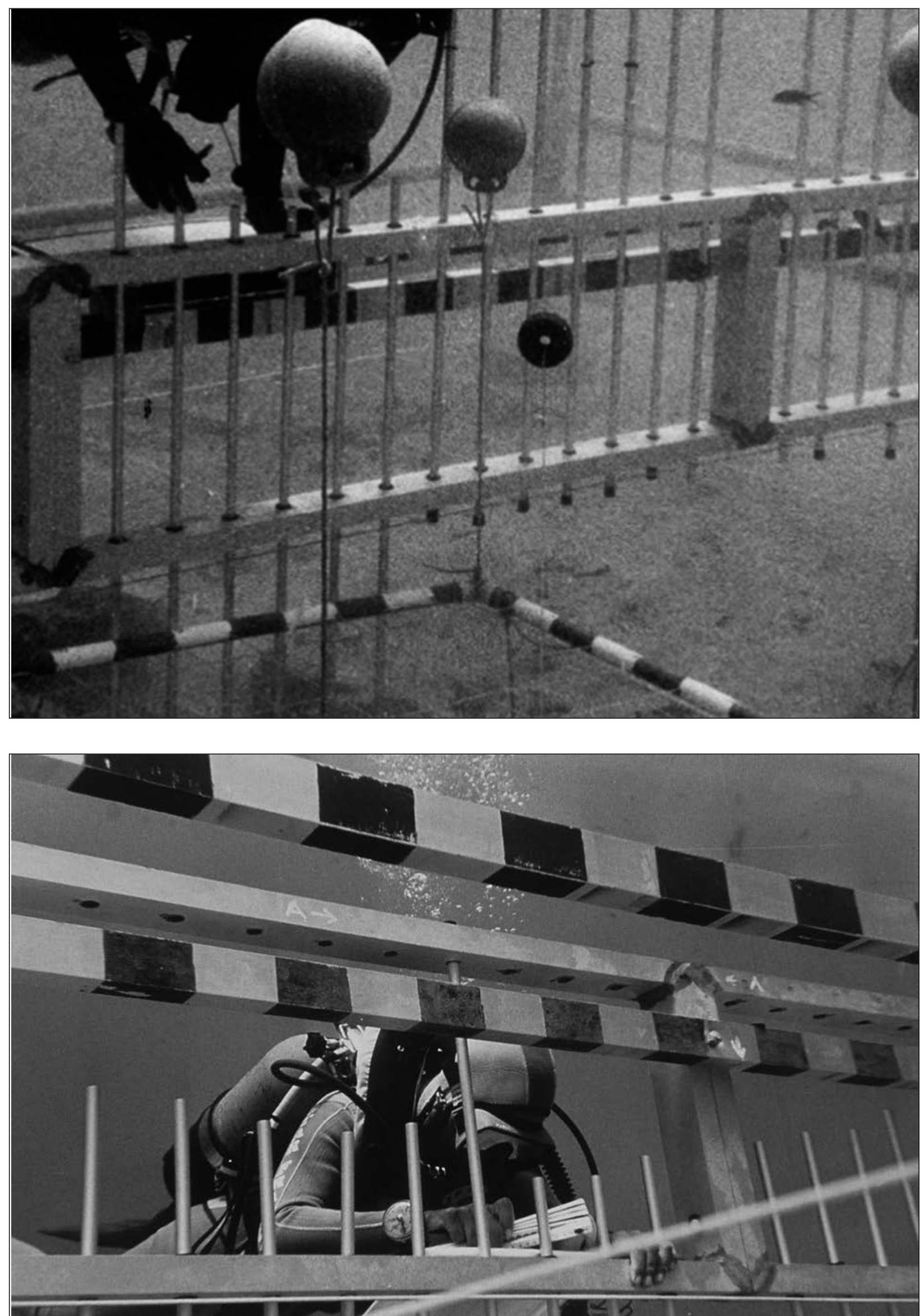

Figuras 7, 8 y 9. Estructura de excavación, dibujo y fotografía instalada en la campaña de 1992 (Fotos: José Latova). 


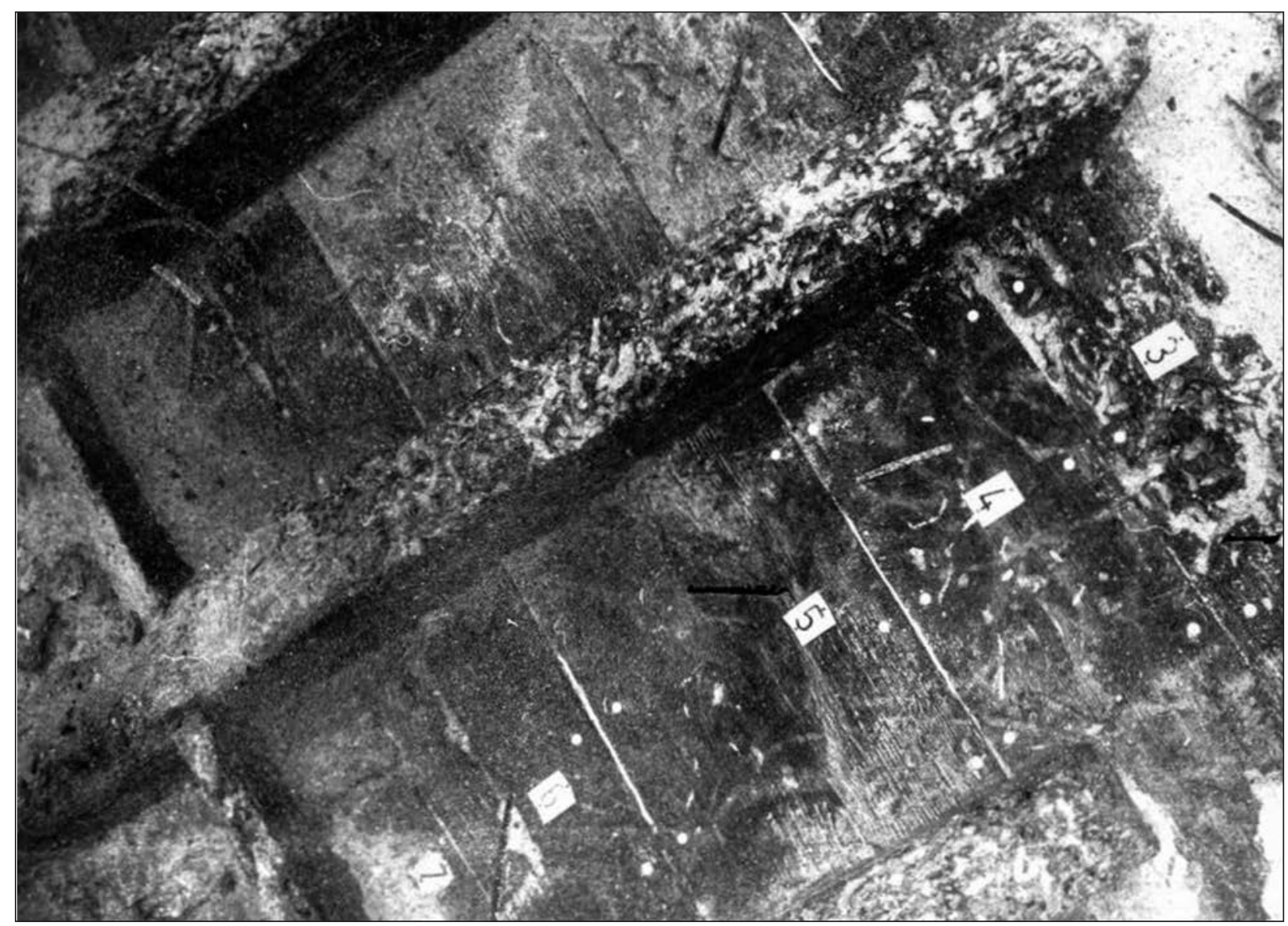

Figura 10. Etiquetado de los distintos elementos del casco para su posterior identificación (Foto: José Latova).

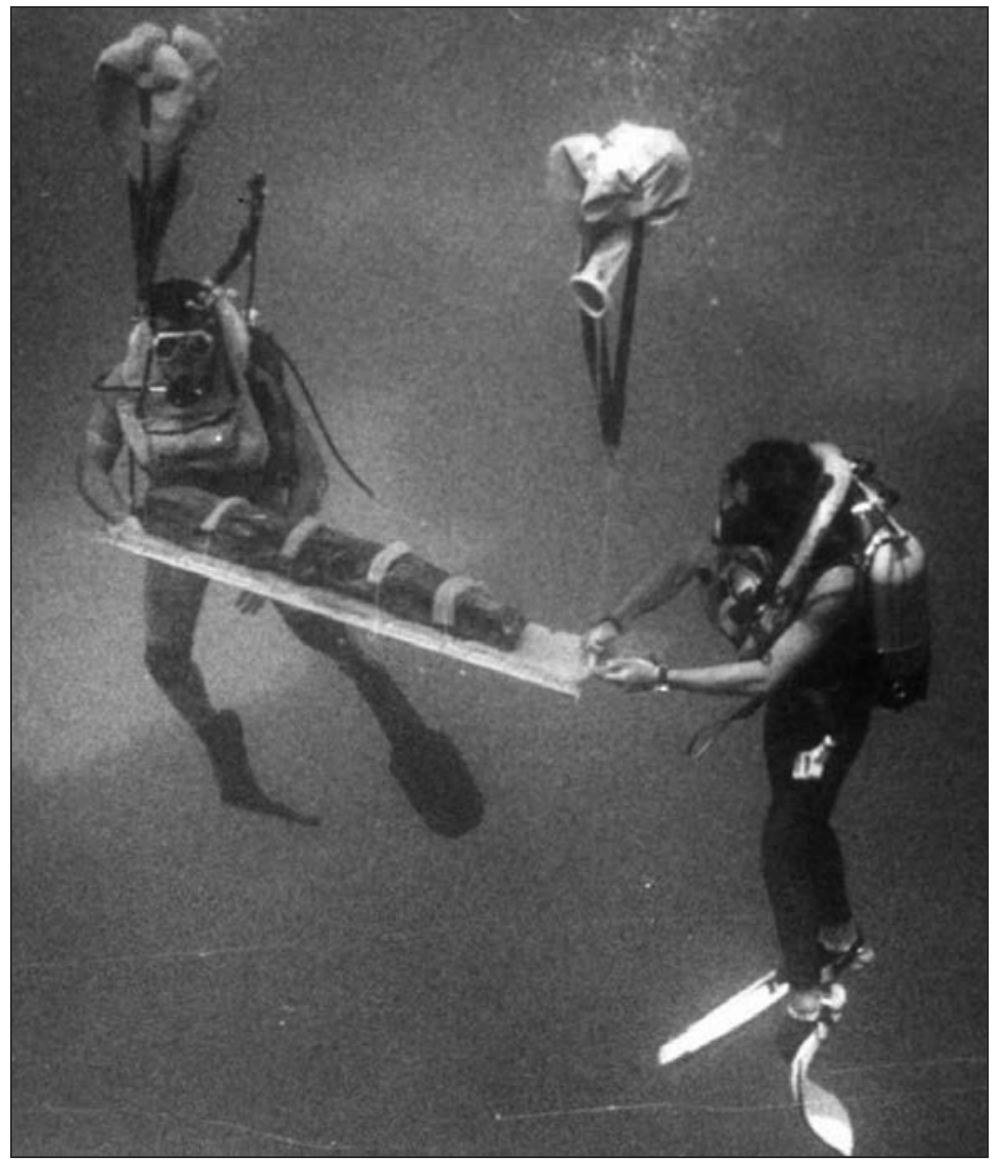

Figura 11. Extracción por parte del equipo de restauración de un fragmento de cuaderna para su estudio en superficie (Foto: José Latova). 


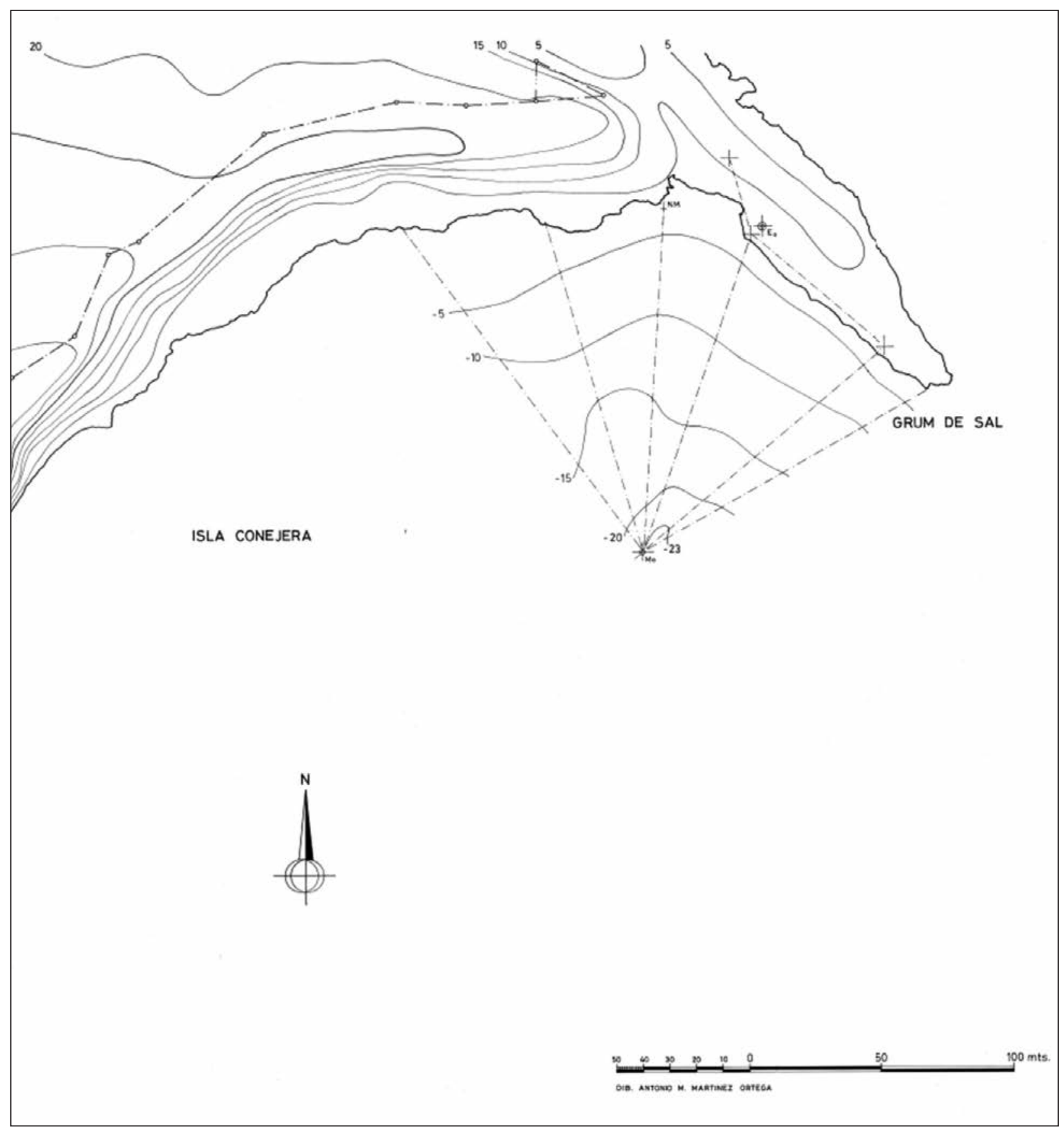

Figura 12. Batimetría del fondeadero de Grum de Sal y ubicación del barco romano (Dibujo: Antonio Martínez).

La zona Noreste del casco, presenta un estado de conservación muy superior a la zona Sur y Suroeste, en las que la madera aparece dispersa y muy fracturada. Los restos localizados pertenecen al forro exterior del casco, la quilla, elementos transversales, entremiches situados entre cuaderna y cuaderna, puntales ubicados a uno y otro lado de los entremiches y algunas tracas del forro exterior fuertemente fracturadas. En total, fueron excavados unos 65 metros cuadrados de la parte mejor conservada del yacimiento (Figura 13).

Además de una gran destrucción antrópica, los restos de este barco han sufrido una serie de fracturas y desplazamientos que han ido abriendo la estructura del casco a partir de la quilla. En nuestra opinión, este mercante se hundió con la proa hacia el Noreste, depositándose en un fondo con doble pendiente sobre el costado de estribor. La carga debió desplazarse hacia este costado rompiendo al cabo de un tiempo la estructura del casco y dispersando su carga a favor de la pendiente. Una parte de las ánforas del costado de babor debió quedarse in situ, protegiendo la madera de este costado. Los restos del costado de estribor han desaparecido, únicamente encontramos una traca fracturada, seguramente de la aparadura, y restos de tracas que aparecieron en las catas de sondeo superficial realizadas al sur del yacimiento. 


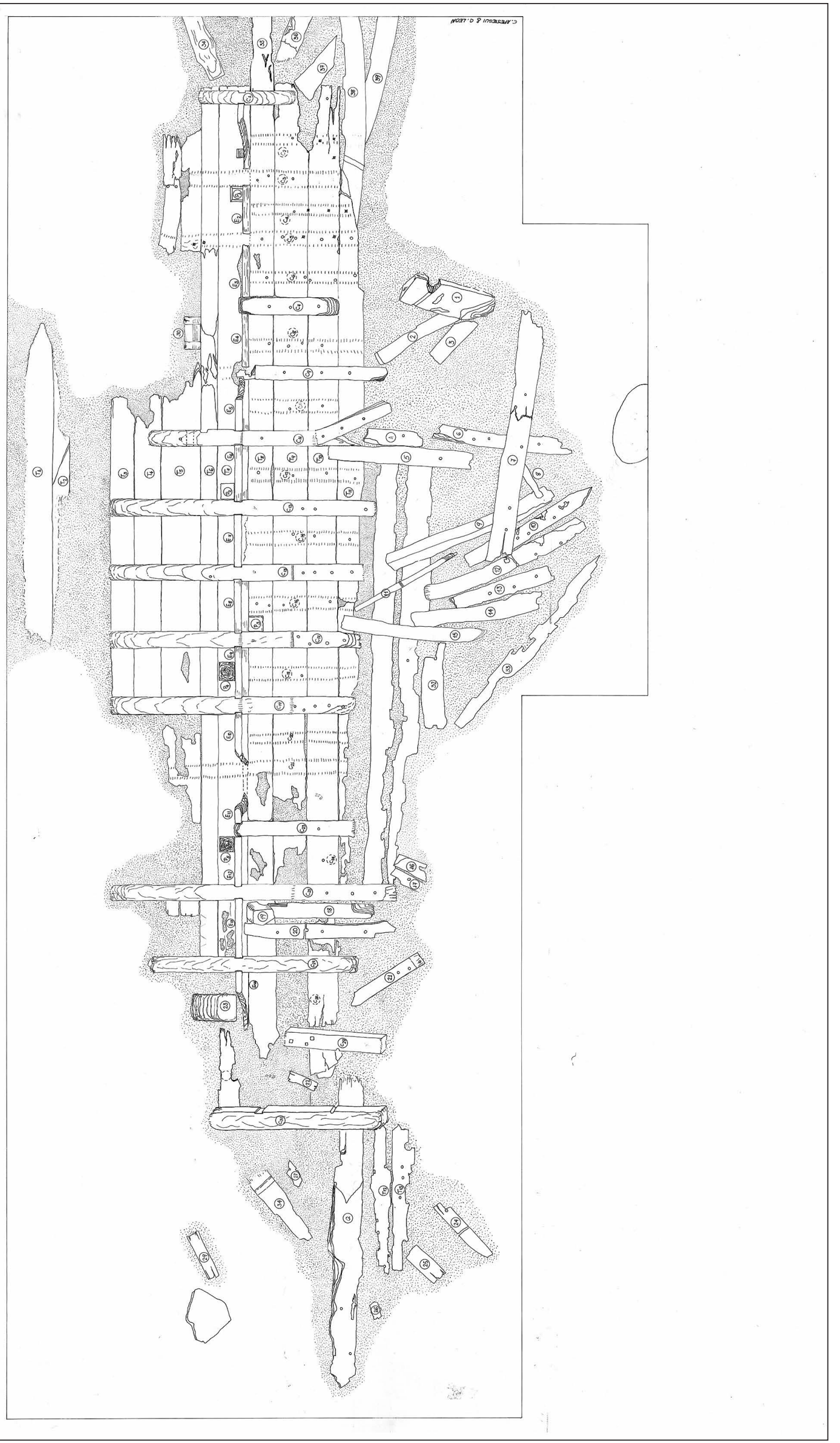

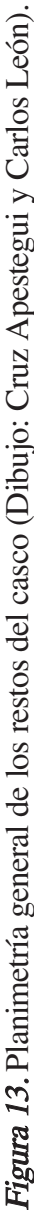




\section{ORIGEN DEL BARCO Y EL CARGAMENTO}

Los primeros dibujos de las ánforas extraídas del barco de Grum de Sal se presentaron en el segundo informe de excavación de Vilar-Sancho y Mañá Angulo (1965), siendo entonces descritas pero no identificadas (Vilar y Mañá, 1964: 187). Los estudios más recientes indican que se trata de un cargamento de ánforas Dressel 14b, con un largo cuello en forma de embudo exvasado unido al cuerpo por una curva continua y hombros poco marcados. El cuerpo o panza, más o menos cilíndrico u ovoide, muy irregular, acaba en un pivote cónico hueco. Tienen asas robustas y largas con una acanaladura central al exterior y una gran variedad de tipos de bordes (Martínez y León, 1993: 265-266). En la campaña de 1991, se encontraron vértebras de lubinas (Dicentrarchus labrax) y merluzas (Merluccius merluccius) de gran tamaño propias de aguas frías (Figura 14).

Este tipo de ánforas parece ser una imitación Lusitana de las Dressel 14a producidas en la Bética. En las Termas del Nadador, en Ostia, las Dressel 14a son sustituidas por las Dressel $14 b$ a finales del siglo I, aumentando su presencia a lo largo del siglo II d. C. Las excavaciones submarinas de yacimientos como Saint-Gervais o Cap Bénat, con cargamentos de Dressel 14b, indican que también la zona Este del golfo de León podría ser receptora de este tipo de ánforas (Figura 15).

En cuanto a los centros de producción, han sido excavados $\mathrm{y}$ publicados varios hornos de ánforas Dressel 14b en la desembocadura del río Tajo y del Sado destinados al transporte de preparados piscícolas. En la margen izquierda del Tajo se han excavado varias industrias de salazón e importantes alfares con ánforas Dressel 14b (Lópes y Mayet, 1990: 299-301).

Estos datos nos llevan a pensar en una ruta comercial que tuviera como origen la desembocadura del río Tajo o del Sado, y como destino Roma o el Este del golfo de León, ambos con escala en Ibiza. En este sentido, hay que destacar el papel del islote de Conejera como lugar de fondeo en medio de esta ruta, documentado por los hallazgos arqueológicos y por las fuentes escritas que nos hablan de este fondeadero e incluso de un punto de aguada.
Pascual Madoz, en su obra Diccionario Geográfico-Estadístico-Histórico de España y sus Posesiones de Ultramar, denomina Conejera la Grande a la actual isla de Conejera, de la que dice "sirve para el ganado, aunque está expuesta a la codicia de los corsarios" y cita la existencia de dos fondeaderos, "uno en la ensenada Este, y otro en la punta Sureste", que corresponde al resguardo de la punta de Grum de Sal (Madoz, 1850, VI: 561).

\section{LAS CAUSAS DEL HUNDIMIENTO}

Cuando habla de los pasos marítimos entre estas islas, Madoz describe la peligrosidad del paso existente entre la isla de Bosque y la llamada Punta de las Piedras, la actual punta del Embarcador, aconsejándolo sólo para pequeñas embarcaciones de remos, y también el paso entre el islote de Bosque y el de

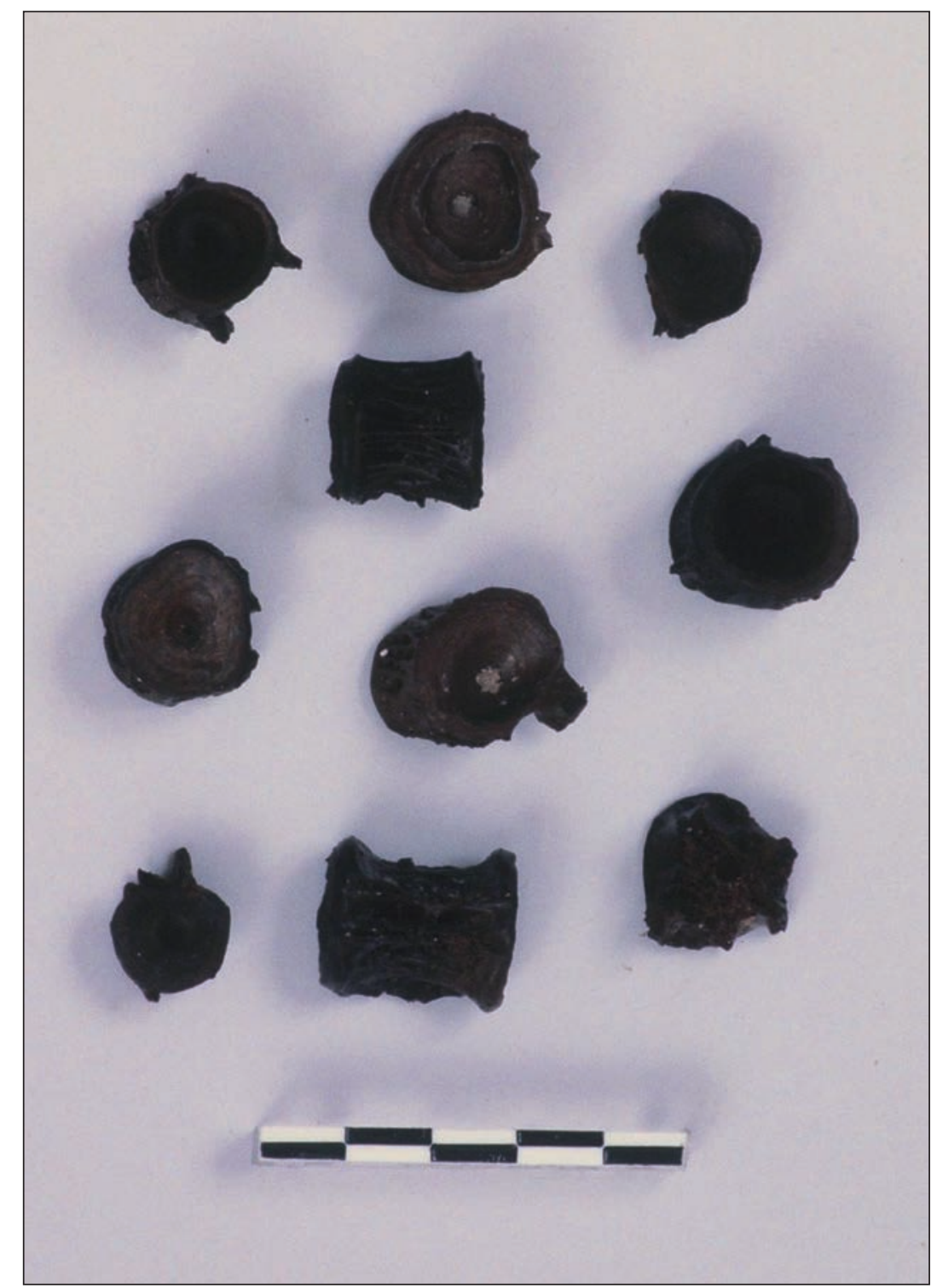

Figura 14. Vértebras de lubinas y merluzas recuperadas en la campaña de 1992 (Foto: Pedro Ortíz). 

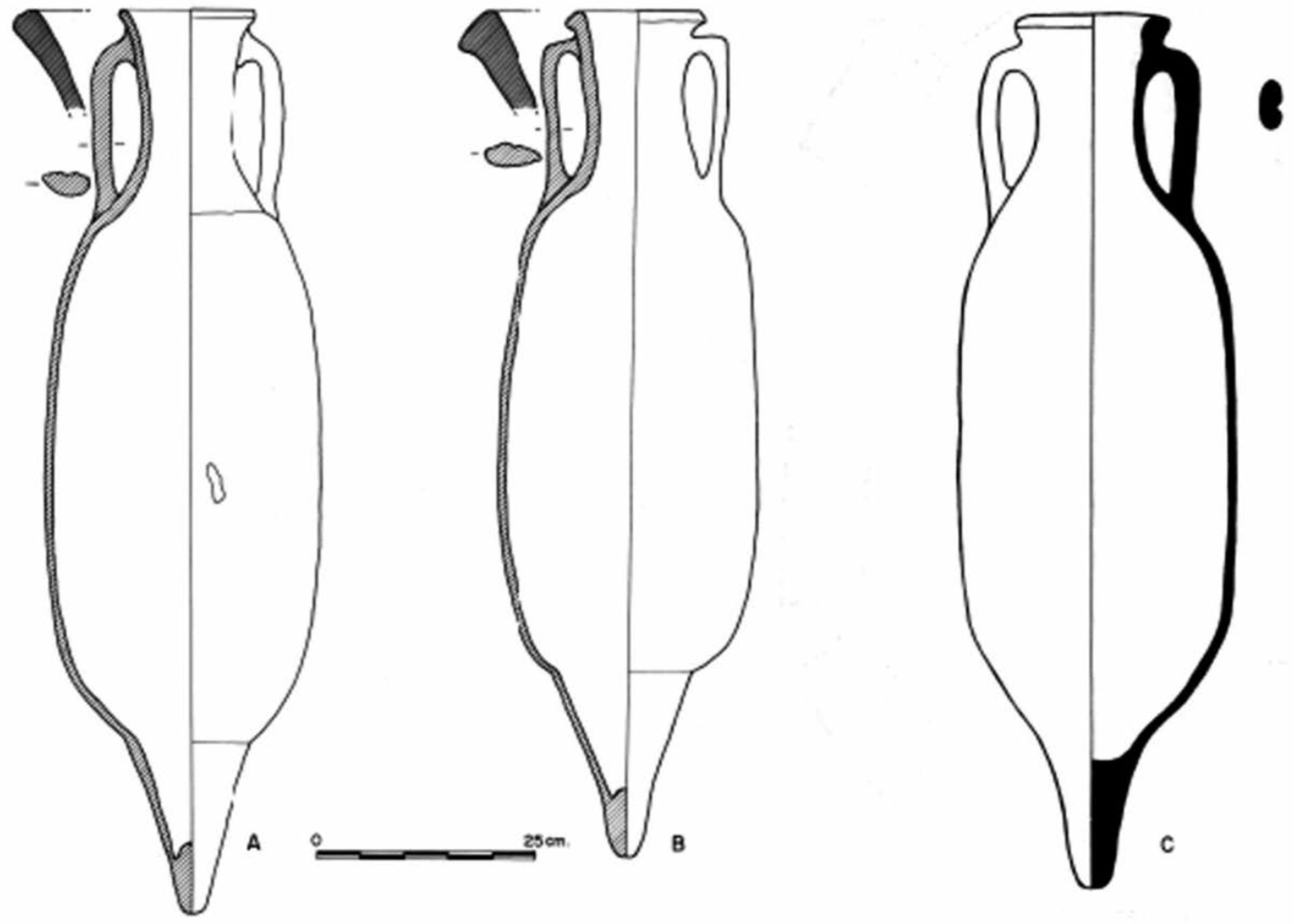

Figura 15 Ánforas Dressel 14 b, A y B, de Grum de Sal, C de Cap Benat I (Según Martínez y León, 1993).

Conejera, del que dice que es "peligroso" y aconseja "pasar sólo embarcaciones menores, si se tiene mucha práctica" mientras para las grandes embarcaciones armadas aconseja "el paso entre La Conejera Grande y la del Esparto, o entre estas dos y Las Bledas" (Madoz, 1850: 373).

Si el mercante de Grum de Sal se dirigía al puerto de Roma, ruta muy probable como hemos visto, a tenor de su cargamento, y tanto si pretendía buscar la bahía de San Antonio, como si su intención era proseguir tras hacer aguada y fondeo hacia el estrecho de Bonifacio, después de dejar a su espalda el litoral de la Península a la altura del cabo de San Antonio y llegar al oeste de la isla de Ibiza, se encontraría el peligroso paso entre los islotes de Conejera y Bosque, con la barra de roca que une las dos islas que en el centro tiene una profundidad de unos 5 metros, y en los extremos apenas llega a los 30 centímetros. En nuestra opinión, el barco de Grum de Sal debió de chocar con uno de sus pantoques en los denominados Picachos, o en la punta de Cabo Blanch, hundiéndose 300 metros más adelante con la proa hacia el Noreste, en la dirección en la que navegaba (Figuras 16 y 17).

\section{Elementos transversales del CASCo}

Bajo el agua, el casco de este barco presenta dos tipos de elementos transversales: varengas y cuader- nas. Las primeras son elementos constructivos o estructurales, según el método de construcción del casco, que se colocan atravesando la quilla. El barco de Es Grum de Sal presenta unas varengas extremadamente planas, es decir, con un fondo bastante plano. Todas ellas han aparecido desplazadas de su lugar original del que aún quedan las improntas (Figura 18).

El segundo elemento transversal que compone la estructura de este casco son las cuadernas, en realidad, la primera ligazón de cada cuaderna. Estos elementos que forman el entramado transversal del casco aparecieron perfectamente conservados en su posición original aunque algunas de ellas están fragmentadas por diversos puntos débiles de la pieza. En algunos casos, las cuadernas se han perdido y ha quedado su huella claramente marcada en la parte interna del casco. En la planimetría del casco hemos denominado con la abreviatura ' $\mathrm{C}$ ' a todos los espacios en los que corresponde una pieza transversal, aunque ésta no se conserve o esté desplazada, de manera que tenemos en total 31 espacios para elementos transversales. De estos 31 espacios tan sólo 13 están ocupados por sus elementos correspondientes, mientras que los demás son improntas de los elementos transversales que, en algunos, corresponden con elementos sueltos desplazados de su lugar original. 

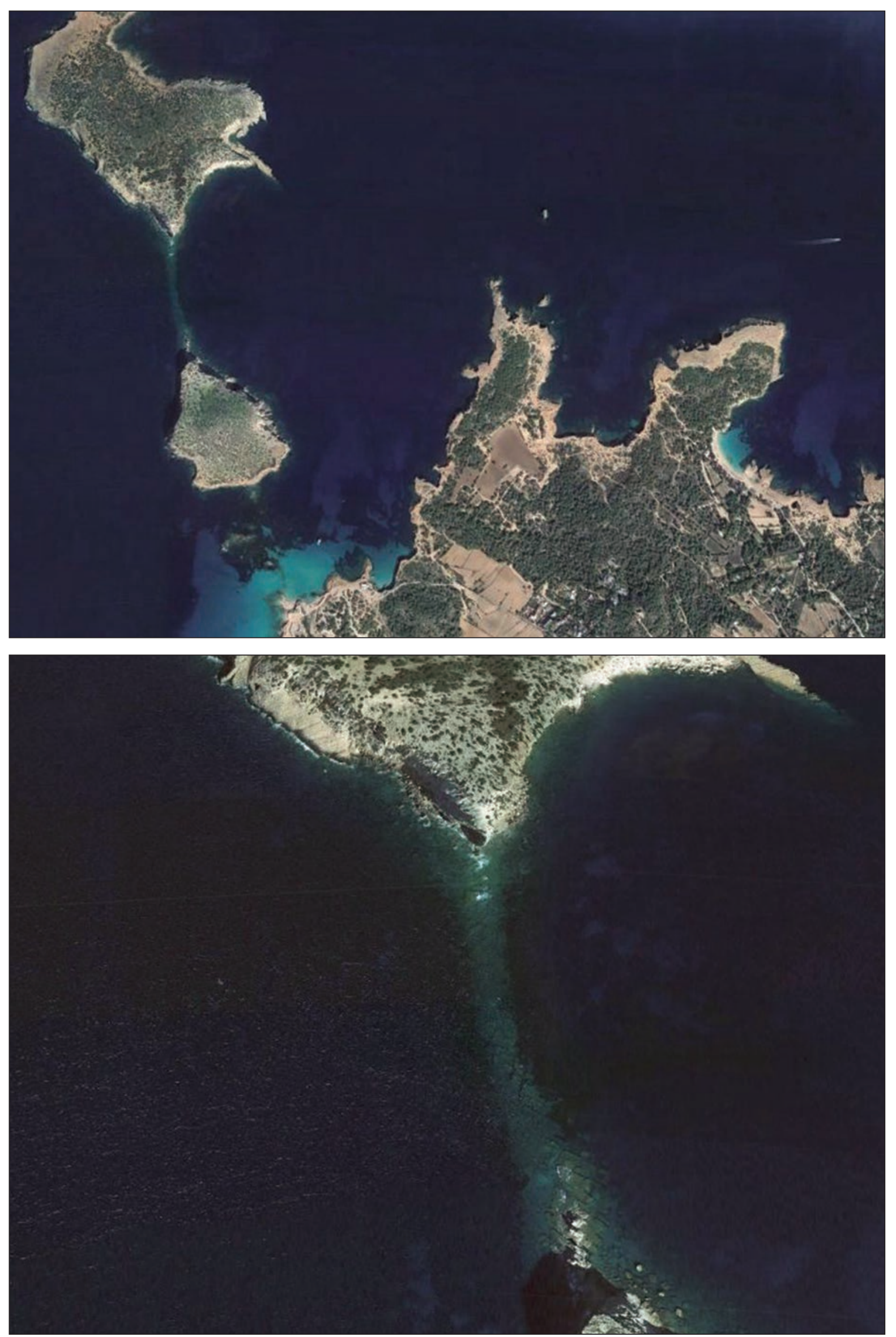

Figuras 16 y 17. Vistas aéreas del paso entre la isla Conejera y Bosque (Fotos: Google Earth). 


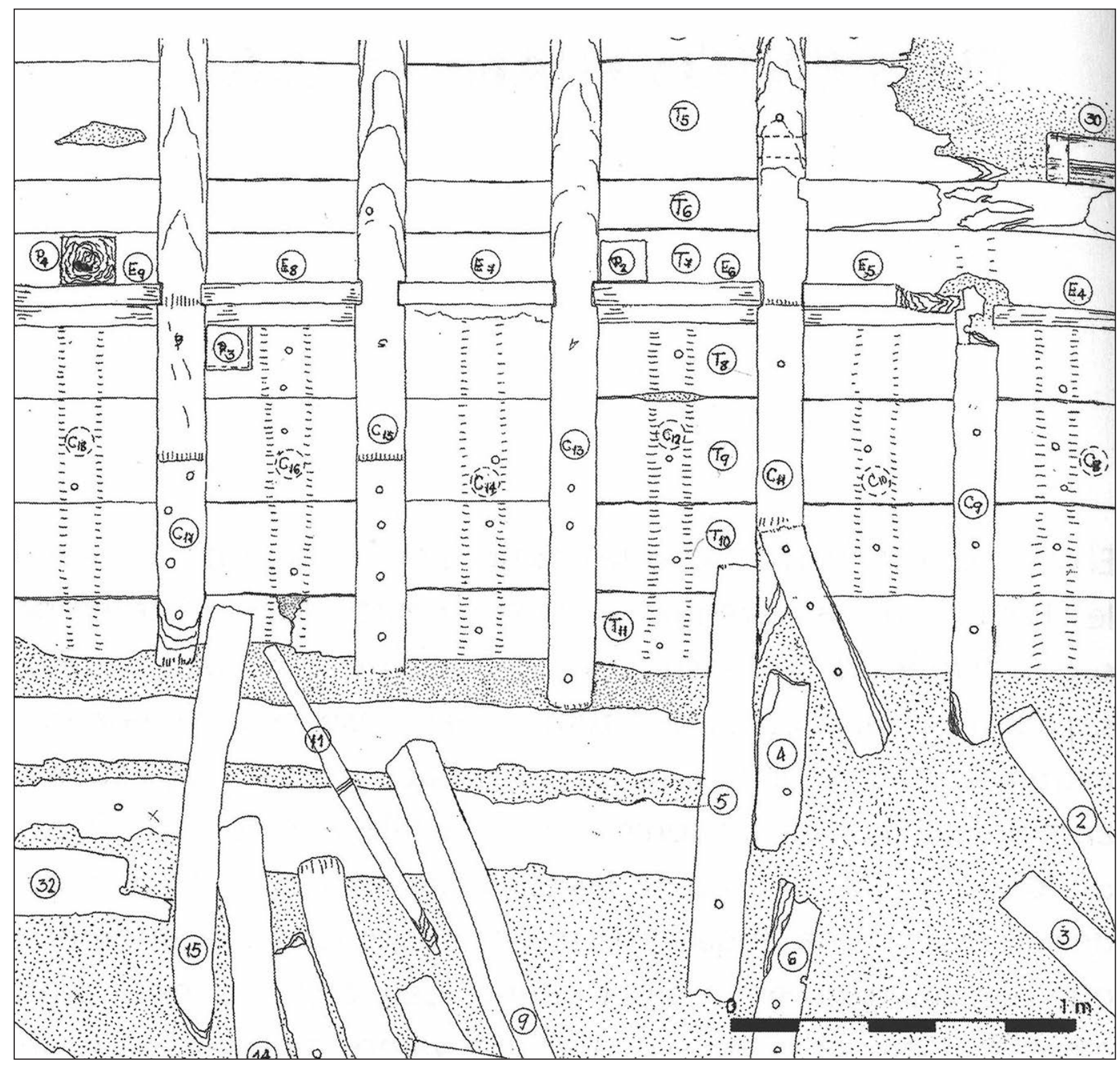

Figura 18. Detalle del casco entre las cuadernas C9 y C17 (Dibujo: Cruz Apestegui y Carlos León).

Lo primero que observamos es la perfecta alternancia entre cuadernas y varengas.

Mientras las cuadernas llegan sólo hasta la altura de la quilla sin sobrepasarla, las improntas de las varengas no sobrepasan nunca los entremiches longitudinales, de los que más adelante hablaremos, que quedan encajados en las ranuras o cajeras inclinadas practicadas en el canto de las ligazones. Tan sólo una pieza (C31) parece reunir ambas características, ya que tiene dos entalles para los entremiches y a la vez sobrepasa la quilla. La explicación podría ser que nos hallamos en una zona en la que el casco comienza a afinarse, seguramente por la popa (Figura 19).

La clara entre elementos transversales a la altura de la quilla es de unos 15 a 17 centímetros (dimensión normal entre los barcos romanos que suele estar entre 15 y $22 \mathrm{~cm}$ ). Al norte de los entremiches esta clara es de unos 45 centímetros, al no existir huella alguna de elementos intermedios entre las cuadernas. Algo similar puede observarse en la estructura del barco de County Hall (Marsden, 1974, fig. 1), en el que las varengas, separadas unos 14 centímetros sobre la quilla, se alternan con las cuadernas que forman el costado del casco con una clara de unos 42 centímetros.

Todas las cuadernas tienen unos entalles laterales inclinados que sirven de guía y alojamiento a los entremiches (Figura 20). Además de estos elementos, las cuadernas presentan una serie de cabillas y clavos que unen, en unos casos, la cuaderna con el forro externo, y en otros, el forro interno con las cuadernas sobre las que apoya. Desde los entremiches al extremo norte del costado del barco las cuadernas se van arrasando paulatinamente. Los extremos están fractu- 


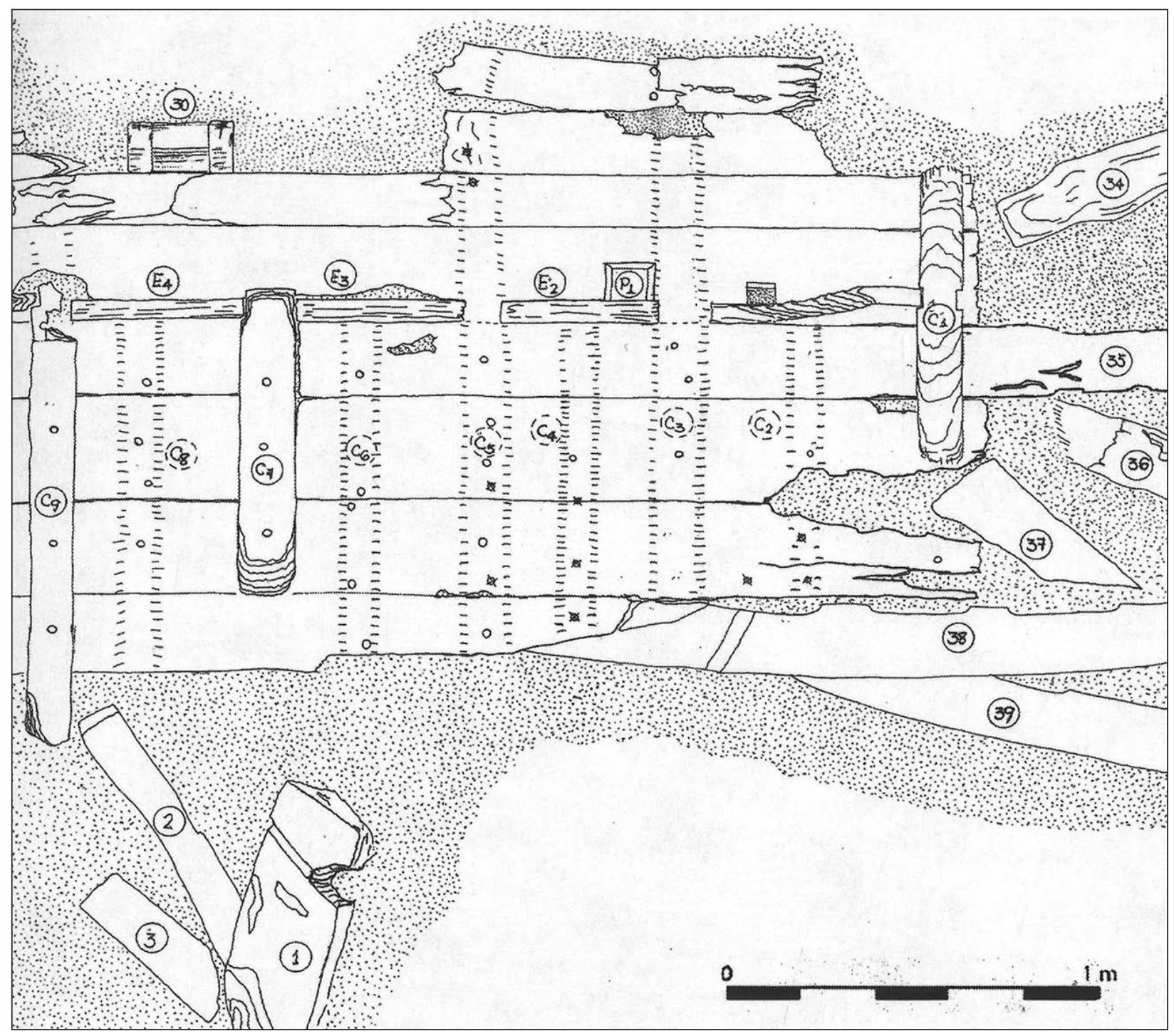

Figura 19. Detalle del casco entre las cuadernas C4 y C9 (Dibujo: Cruz Apestegui y Carlos León).

rados donde parece terminar la ligazón, siendo un lugar de fácil fractura del casco. Desde la línea de los entremiches hacia el Sur, las cuadernas presentan su parte más completa, a veces rehundida por la existencia de alguna pieza superior longitudinal de gran tamaño (C15, C17 y C19) (Figura 21).

\section{Elementos longitudinAles del CASCO}

El barco de Grum de Sal conserva once tracas del forro exterior perfectamente ensambladas y formando estructura con las cuadernas, los puntales y los entremiches. Su grosor, de unos 5 centímetros, es similar al de otros barcos romanos (Fiumicino, Chrètienne A, Yassi-Ada IV, County Hall, Marseille). La anchura de las tracas es muy variable, entre 20 y 35 centímetros. La traca T6 es notablemente distinta del resto. Dadas sus dimensiones, 13 centímetros de grosor por 15 de anchura, y su posición en el casco, podría tratarse de un cintón (Figuras 22 y 23).
Las tracas del forro están unidas entre hiladas a tope o a testa. La unión se realiza, como es habitual en la construcción naval greco-romana, por medio de lengüetas o llaves que se introducen en sus correspondientes mortajas practicadas en el canto de las tracas. Para asegurar esta unión las tracas son perforadas por dos clavijas cilíndricas que atraviesan las llaves inmovilizándolas.

La distancia entre las mortajas es de unos 8-12 centímetros, distancia muy habitual en otros barcos romanos. Las lengüetas tienen una forma casi rectangular con las aristas recortadas para poder entrar mejor en las mortajas. Las dimensiones aproximadas son de $12 \mathrm{~cm}$ de profundidad, $6 \mathrm{~cm}$ de anchura y 0,7 $\mathrm{cm}$ de espesor. En comparación con otras naves de época romana, estas dimensiones se acercan mucho a las de Laurons II, County Hall o Palamós. Las clavijas de unión tienen un diámetro de 1,2 centímetros y presentan una superficie afacetada. Además del 


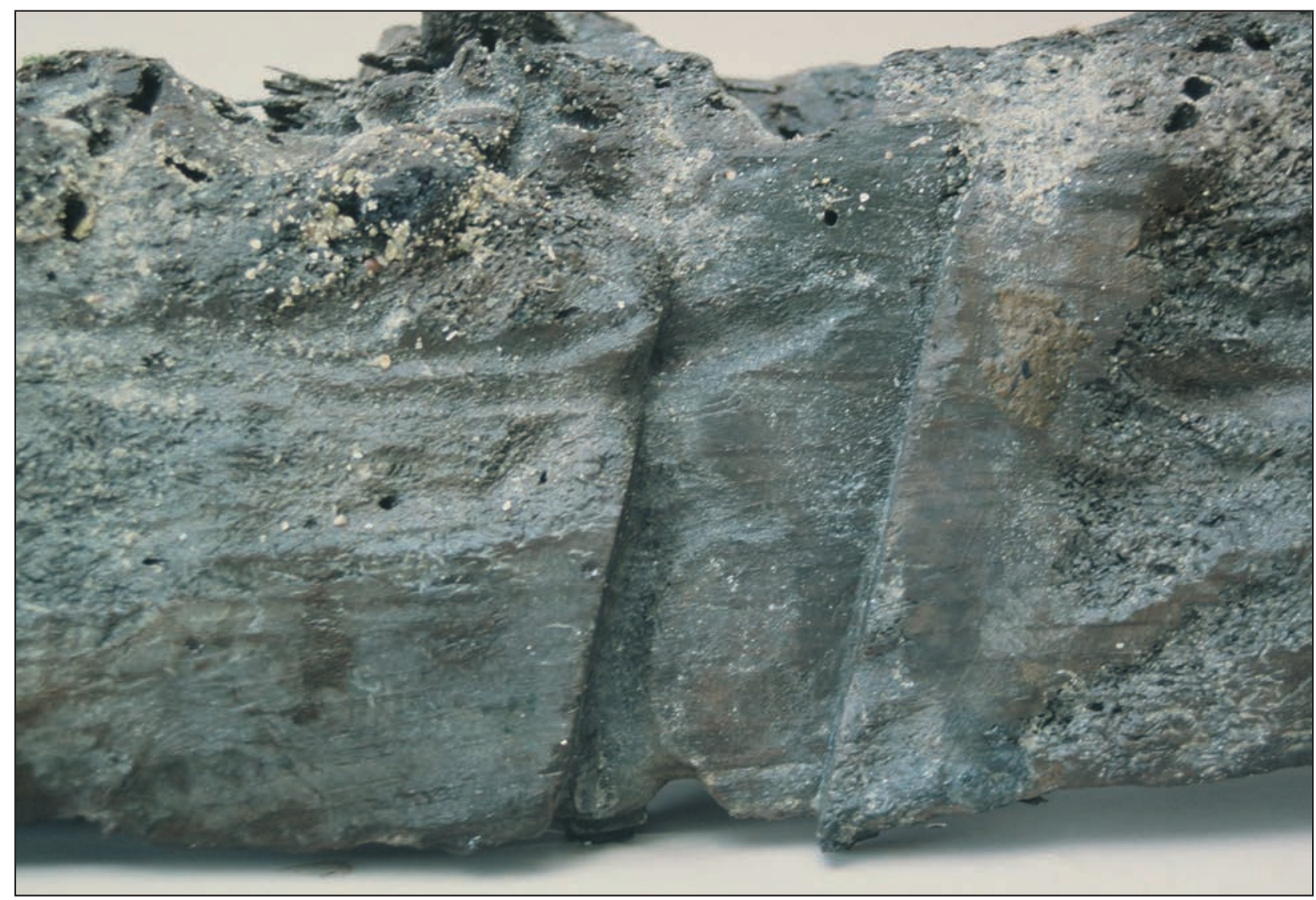

Figura 20. Fragmento de cuaderna con entalle lateral para sujeción de los entremiches (Foto: Pedro Ortiz).

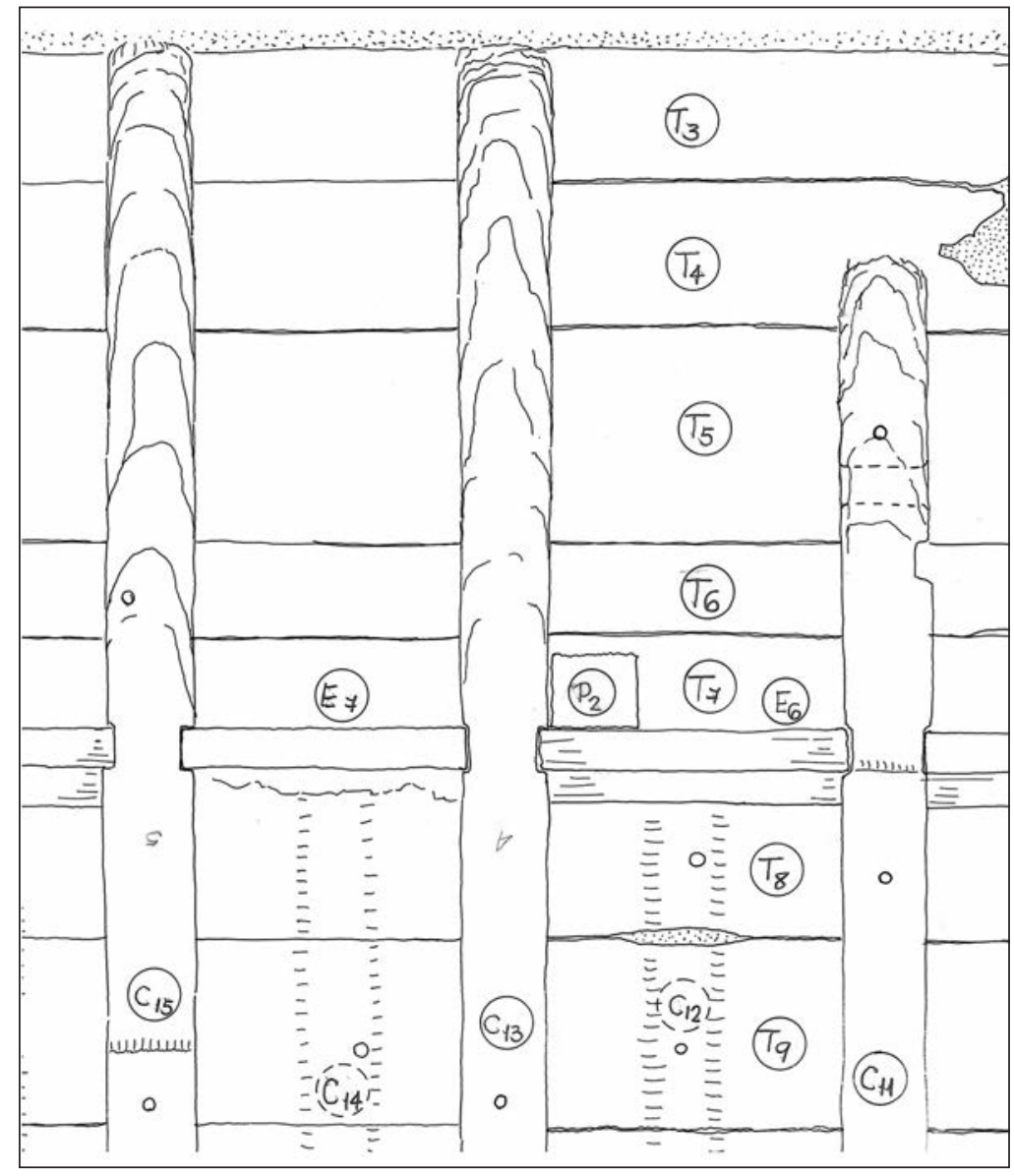

Figura 21. Detalle del casco entre las tracas T3 y T9 (Dibujo: Cruz Apestegui y Carlos León). 

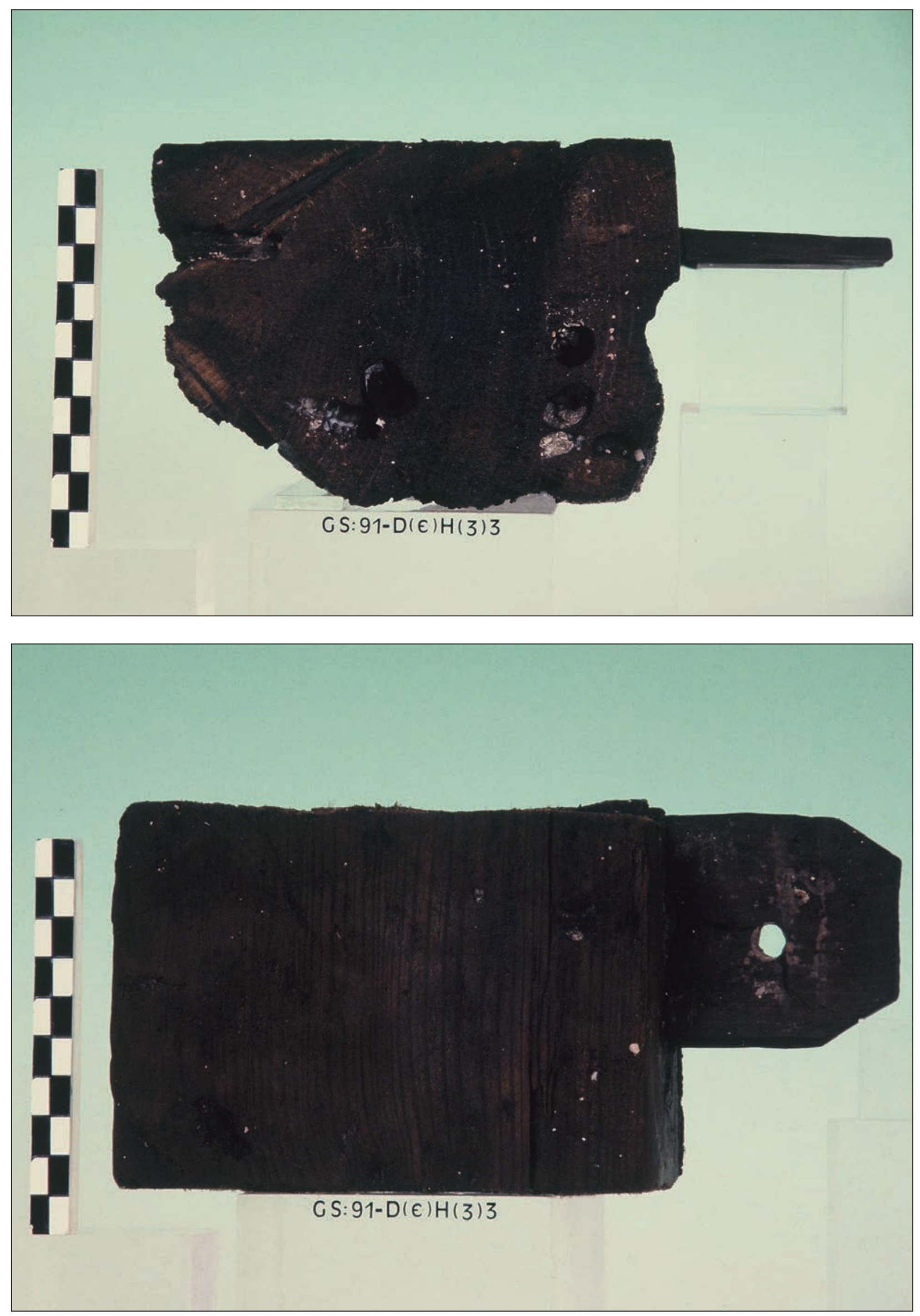

Figuras 22 y 23. Fragmento de cintón del forro exterior T-6. 
ensamblaje entre las hiladas del forro, las tracas conservan restos de clavos metálicos de hierro y bronce de sección cuadrada $(1 \times 1 \mathrm{~cm})$ utilizados para unir las tracas con las cuadernas. También quedan restos de cabillas cilíndricas de madera con superficie afacetada, introducidas posiblemente desde el exterior del casco, con una sección de 1,5 centímetros, que unen las tracas con las cuadernas.

En los sondeos transversales realizados sobre el yacimiento apareció, en muy mal estado de conservación, una pieza longitudinal con una escuadría muy superior a las demás tracas del forro, aproximadamente de 20x15 centímetros. Esta pieza se hallaba ligeramente inclinada hacia el Sur, presentando una superficie superior plana con clavijas en la parte superior e indicios de restos de mortajas practicadas en los laterales, aunque sin alefriz. Esta pieza presenta además orificios de cabillas de madera en su cara superior. Sus dimensiones, similares a las de otros barcos romanos (County Hall, Yassi-Ada IV), nos llevan a pensar que ésta sea la quilla del navío (Figura 24).

Los elementos longitudinales más característicos y singulares de esta embarcación romana son, sin duda, las 14 piezas introducidas entre cuaderna y cuaderna, a las que hemos denominado entremiches. Este término no define ningún elemento concreto del casco de un barco, sino que hace referencia a cual- quier pieza que se coloca en sentido longitudinal entre dos elementos transversales. El alojamiento de estas piezas entre las cuadernas se hace por medio de un entalle en el lateral de éstas inclinado unos 10 grados hacia el norte. Estos entalles, uno a cada lado de las cuadernas, permiten encajar perfectamente estas piezas de madera (Figura 25).

Las dimensiones longitudinales de los entremiches no son exactamente iguales. Su variación es de unos 10 centímetros aproximadamente entre la mayor longitud (E1) y la menor (E2). En nuestra opinión se trata de elementos con una doble función, de refuerzo para evitar el desplazamiento lateral de las cuadernas y como arranque de un mamparo desmontable de separación de dos espacios dentro de la bodega.

\section{Puntales verticales}

El casco de este mercante romano presenta cinco pequeños puntales o postes verticales que apoyan en dos tracas del forro exterior (T7 y T8), algo realmente inusual dado que los puntales apoyan normalmente en la sobrequilla, pieza de un gran grosor y muy resistente que soporta y distribuye también los esfuerzos que realiza la coz del mástil.

Otro aspecto destacable es la ubicación de estos puntales en la estructura del casco. Los puntales del caso del barco de Grum de Sal se sitúan a uno y otro

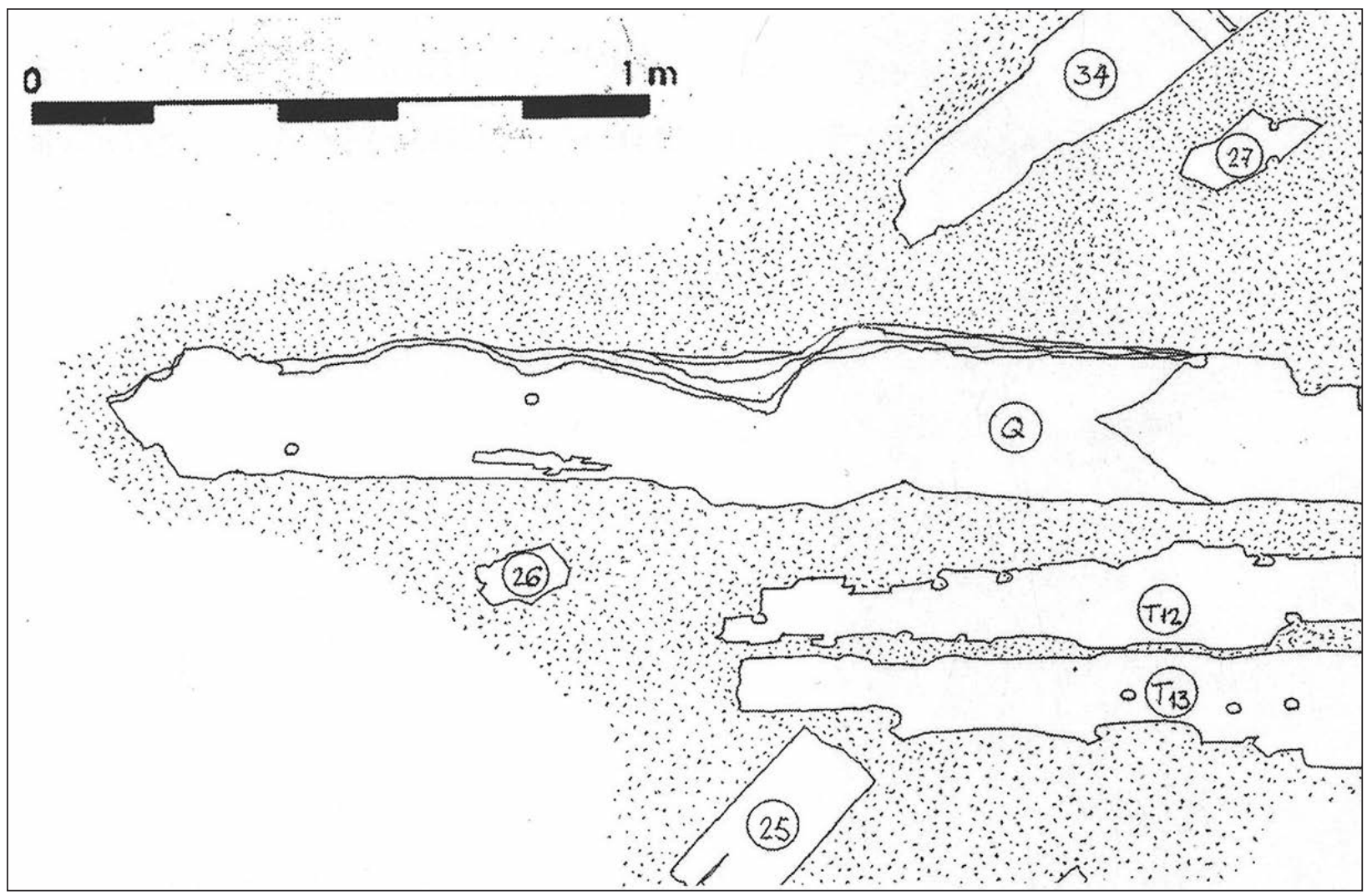

Figura 24 Detalle de la quilla (Dibujo: Cruz Apestegui y Carlos León). 


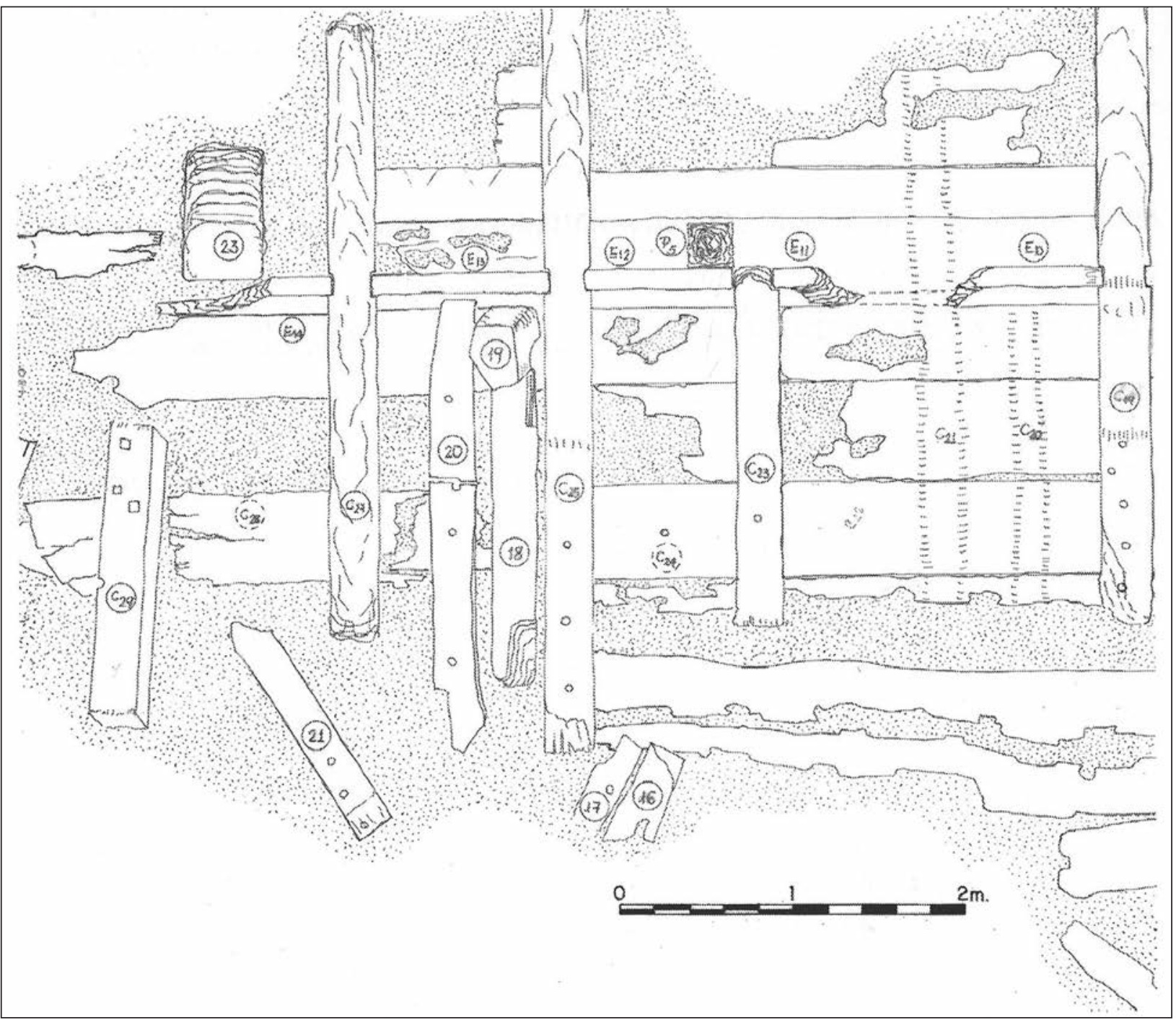

Figura 25. Detalle de los entremiches entre las varengas (Dibujo: Cruz Apestegui y Carlos León).

lado de los entremiches. P1, P2, P4, y P5 están colocados al norte de los entremiches, en la traca $\mathrm{T} 7$, mientras que P3 está sobre la traca T8, al sur de los entremiches. De los cinco puntales indicados en el plano del casco, dos de ellos (P1 y P3) están arrasados por la base, mientras que los demás lo están a la altura de las cuadernas y los entremiches.

\section{Elementos Aislados}

Aparte de los elementos que conforman la estructura principal del casco, el yacimiento de Grum de Sal conserva una gran cantidad de piezas de madera desplazadas repartidas por la superficie del fondo. Algunas de estas piezas han sido identificadas como elementos concretos del casco y se ha podido estimar su posición original en la estructura.

En la zona Sur del yacimiento, encontramos una serie de elementos sueltos, que en su mayoría hemos identificado como varengas desplazadas. En total, unas 14 piezas con escuadrías similares a las de las cuadernas, que podrían corresponderse con los espacios existentes entre cuadernas, en los que se han hallado improntas de elementos transversales desaparecidos. Además de estas piezas, se han encontrado fragmentos de una traca del forro exterior, partida longitudinalmente en dos, que corre paralela a las demás tracas del forro y que ocupa desde $\mathrm{C} 13$ hasta C25, pudiendo corresponderse más al oeste con las piezas 33 y 34 . Estos fragmentos de traca están separados de la estructura principal del casco, concretamente de T11, unos 15 centímetros, aunque en algunos lugares las distancias son notablemente mayores. Al oeste, las piezas 33 y 34 están muy cercanas a la quilla, pudiendo corresponderse con las aparaduras.

La pieza número 7, situada en sentido longitudinal sobre el conjunto de las posibles varengas desplazadas, tiene el grosor de una traca del forro, pero no presenta mortajas ni restos de llaves y clavijas de unión. Esto nos hace pensar que pudiera tratarse de un palmejar del plan de la bodega. 


\section{INTERPRETACión DE LA ESTRUCTURA DEL CASCO.}

En nuestra opinión, la estructura del barco de Grum de Sal estaría formada por un forro externo con un cintón (T6) en el pantoque, una serie de varengas que atravesarían la quilla y unas ligazones en las que se encajarían unos elementos que formarían una tablazón vertical (entremiches) para separar dos espacios internos en la bodega del barco. Los puntales servirían para encajar un mamparo vertical del que desconocemos su altura. La zona situada sobre el área de la quilla estaría cubierta por un forro interno que ha dejado sus huellas en algunas de las cuadernas (C15, C17, C19), y que se sujetaría por medio de cabillas de madera clavadas desde el interior del casco.

La otra parte de la bodega, desde los mamparos que comenzarían en los entremiches hasta la cubierta, no tendría forro interno, y en él irían seguramente almacenadas las ánforas en tres hiladas, tal y como las halló Vilar-Sancho en su excavación de 1962.

En cuanto al proceso y método de construcción de este mercante, teniendo en cuenta la forma de ensamblaje del forro por medio de lengüetas y mortajas aseguradas con clavijas de madera, nos hallamos ante un principio constructivo claramente sobre forro (Figuras 26 y 27). No se ha hallado ninguna varenga ensamblada a la quilla, por lo que no podemos hablar de la existencia de cuadernas activas propias de la construcción naval alterna que ya está documentada en el siglo II-III d.C. en naves como Laurons II o Lacydon. La distancia entre lengüetas, entre 8 y 12 centímetros, y el grosor de las tracas parecen indicar la necesidad de fortalecer enormemente el forro, tal como se ve en los barcos construidos sobre el forro.

\section{BIBLIOGRAFÍA}

Almagro-Gorbea, M. (1969): "Hallazgos arqueológicos submarinos en la isla de Ibiza", Trabajos de Prehistoria XXVI: 349-355.

Basch, L. (1972): "Ancient Wrecks and the Archaeology of Ships”, I.J.N.A. 1: 1-58.

Casson, L. (1964): “Ancient shipbuilding: new light on an old source". The American Neptune 24: 81-94.

Christensen, A. E. (1973): "L. Basch, Ancient Wrecks and the Archaeology of Ships. A comment.", International Journal of Nautical Archaeology, 2 (1): 140. http://dx.doi.org/10.1111/j.10959270.1973.tb00497.x

Fernández González, F. y C. León Amores (1992): "Arquitectura naval y arqueología Subacuática." En S. Martínez Lillo y J. Blánquez, eds. II Curso de Arqueología Subacuática. Serie Varia 2: 71-82.
Foerster Laures, F. (1988): Construcción naval antigua. Barcelona.

Gassend, J.-M. y J.-P. Cuomo (1982-a): Le Navire Antique du Lacydon. Marsella.

Gassend, J.-M. y J.-P. Cuomo (1982-b): “La construction alternée desnavires antiques et l'épave de la Bourse à Marseille.", Revue Archéologique de Narbonnaise XV: 263-272.

Gassend, J.-M. y J.-P. Cuomo (1985): “Un acquis récent des recherches d'architecture navale: la 'construction alternée' des navires antiques.", VI Congreso Internacional de Arqueología Submarina, Cartagena 1982. Madrid: 343-350.

Gassend, J.-M.; Liou, B. y S. Ximenes (1984): "L'épave 2 de l'Anse des Laurons (Martigues, Bouches-du-Rhône).", Archaeonautica 4: 76-105. https://doi.org/10.3406/nauti.1984.953.

León Amores, C. (1996): "Motones y cuadernales en los barcos greco-romanos.", $3^{\text {a Jornadas de }}$ Arqueología Subacuática en Asturias. Gijón: 83100.

León Amores, C. (2000): Buceando en el pasado. Los grandes naufragios de la Historia. Madrid.

León Amores, C. (2016): Investigaciones Arqueológicas Subacuáticas en el barco romano de Es Grum de Sal, Conillera (Sant Antoni de Portmany, Ibiza). Madrid.

León Amores, C. y P. Cabrera Bonet (1991): "Las naves mercantes romanas.", Saguntum y el Mar. Valencia: 19-25.

León Amores, C. y B. Domingo Hay (1994): "La construcción naval en el Mediterráneo greco-romano." Cuadernos de Prehistoria y Arqueología de la Universidad Autónoma de Madrid, 19: 199-218. http://dx.doi.org/10.15366/cupauam1992.19.008

Mañá de Angulo, J. M. (1984): "Sobre Arqueología Ebusitana.", Trabajos del Museo Arqueológico de Ibiza 12: 174.

Martínez Díaz, B. y León Amores, C. (1993): “La carta arqueológica submarina del litoral de la isla de Ibiza”. En S. Martínez Lillo y J. Blánquez, eds. II Curso de Arqueología Subacuática. Serie Varia 2: 251-275.

Martínez Díaz, B. y F. Saez Lara (1994): “Carta arqueológica del litoral de la isla de Ibiza (Baleares)". Aulas del Mar. Universidad de Murcia: 17-38.

Mardsen, P. (1965): “The County Hall Ship.”, Trans. London and Middlesex Archaeol. Soc., 21.2: 118131.

Mardsen, P. (1974): “The County Hall Ship.”. International Journal of Nautical Archaeology, 3: 55-65. http://dx.doi.org/10.1111/j.1095-9270.1974.tb00858.x 


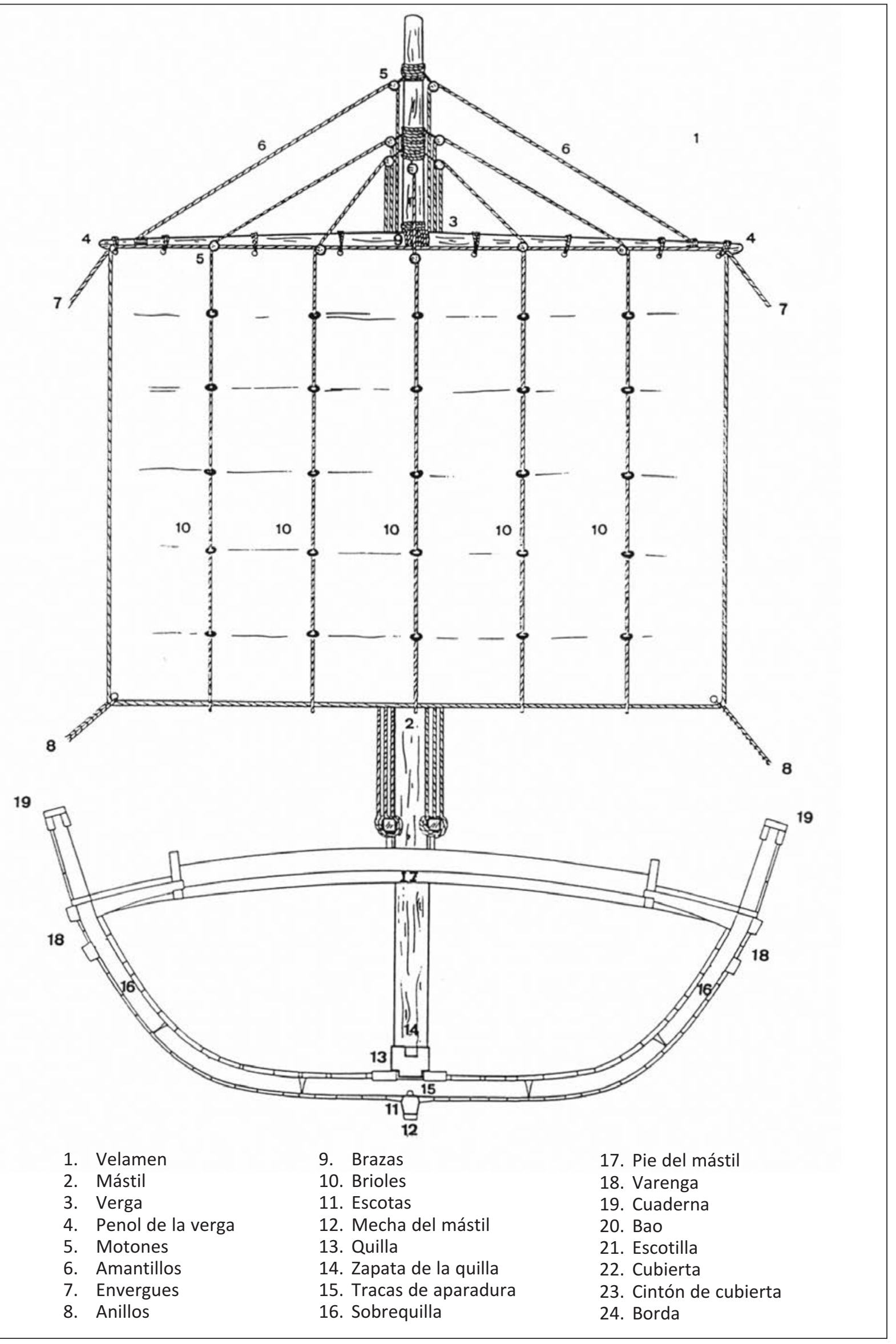

Figura 26. Sección ideal de un barco romano (Dibujo: Carlos León). 


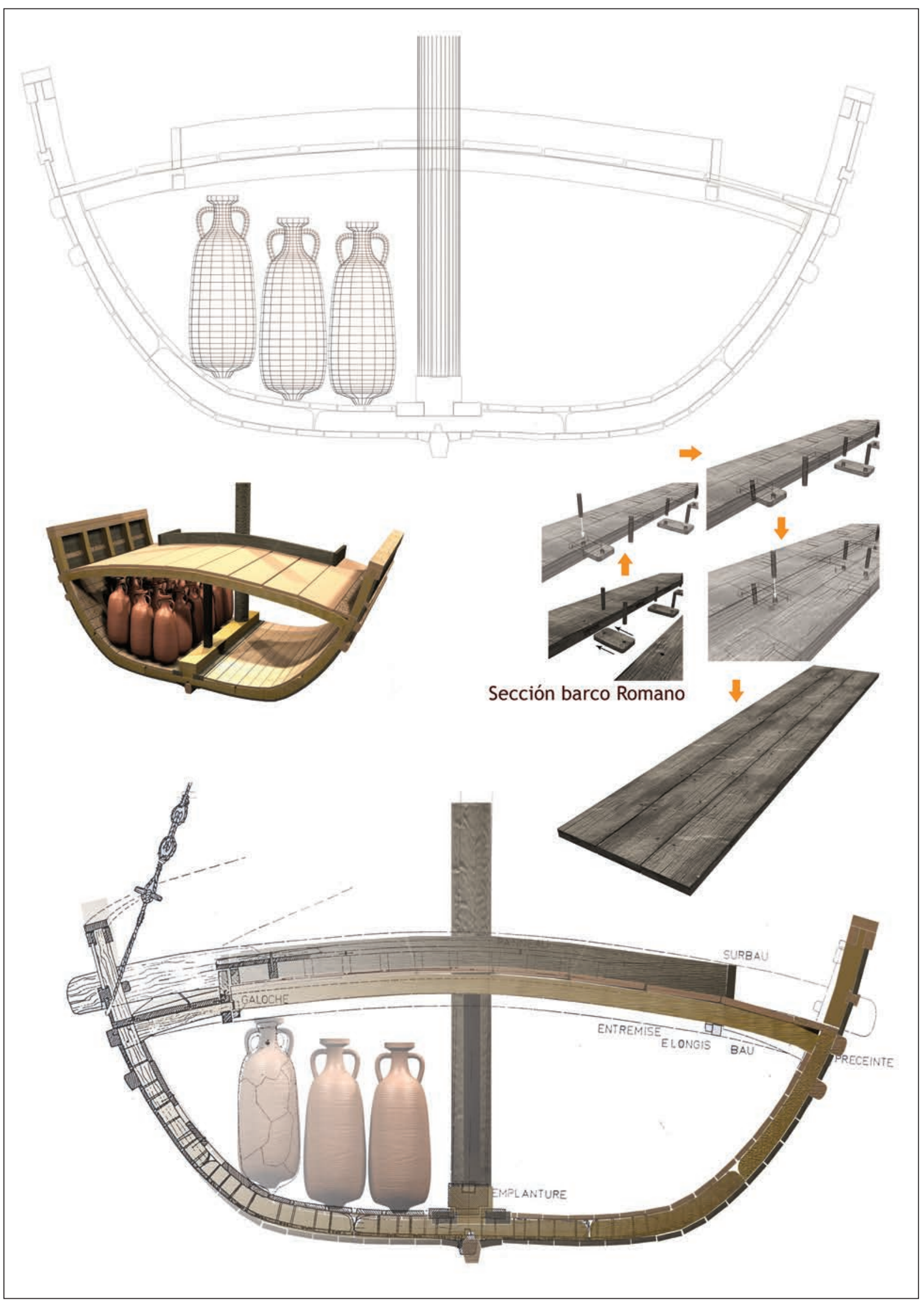

Figura 27. Recreación de la sección de un barco romano y del sistema de unión entre las tracas del forro basado en el barco Laurons II hallado en Marsella (Infografía: José Luís Burgos). 
McGrail, S. y G. Denford (1982): "Boat building techniques, technological change and attribute analysis." En S. McGrail, ed. Woodworking techniques before A.D. 1500. British Archaeological Reports (International Series) 129. British Archaeological Reports. Oxford: 25-48.

Nieto Prieto, J. (1984): Introducción a la arqueología subacuática. Barcelona.

Pallarés, F. (1972): “La primera excavación sistemática del Pecio del Sec (Palma de Mallorca).", Rivista di Studi Liguri XXXVIII: 287-326.

Pomey, P. (1988): "Principes et methodes de construction en architecture navale antique.", Cahiers d'Histoire 33 n 3-4 (Hommage à Jean Rougé). Lyon: 397-412.

Rival, M. (1991): La Charpenterie Navale Romaine. París.

Vargas Ponce, J. (1787): Descripción de las Islas Pithiusas y Baleares. Madrid.

Vilar-Sancho, B. y J.M. Maña Angulo (1964): "Informe sobre la excavación arqueológica en la bahía de San Antonio Abad de Ibiza." Noticiario Arqueológico Hispánico, VI, cuadernos 1-3 (1962): 177-188.

Vilar-Sancho, B. y J.M. Maña Angulo (1965): "Informe sobre la segunda fase de la excavación arqueológica realizada en aguas de la bahía de San Antonio Abad, de Ibiza." Noticiario Arqueológico Hispánico, VII, cuadernos 1-3 (1963): 188-194.

VV.AA. (1985): VI Congreso Internacional de Arqueología Submarina (Cartagena 1982). Madrid.

VV.AA. (1988): La arqueología subacuática en España. Madrid.

VV.AA. (1991): Jornadas de Arqueología Subacuática en Asturias (Gijón 1990). Oviedo.

VV.AA. (1992): Cuadernos de Arqueología Marítima, 1. Cartagena.

Vocabulario de TÉRMINOS NÁUticos Y DE CONSTRUCCIÓN NAVAL

ALEFRIZ: canal o ranura de forma angular practicada longitudinalmente en la quilla; la roda o el codaste para encajar en ella los cantos o cabezas de las tablas del forro.

ANCLA: instrumento de madera o hierro con cepo de plomo o hierro respectivamente. Sirve para evitar que el navío sea arrastrado por el viento o las corrientes al agarrarse al fondo marino.

APARADURA: sobrenombre de las dos primeras tracas del forro exterior, contando a partir de la quilla.

APAREJO: conjunto de palos, vergas, jarcias y velas de una embarcación; conjunto de dos motones o cua- dernales, o un motón y un cuadernal, con un cabo guarnido entre ellos, que permite realizar los trabajos con menor fuerza de la necesaria.

ARBoladURA: conjunto de palos, vergas, mástiles y perchas de una embarcación.

Astilla MUERTA: elevación de los costados de una embarcación; elevación de las varengas sobre la horizontal del canto superior de la quilla. Se mide desde el costado hasta la tangente de la aparadura.

BABOR: banda o costado izquierdo de una embarcación, mirando desde popa a proa.

BAO: cada uno de los maderos que atraviesan de babor a estribor la embarcación y sirven para aguantar los costados y sostener la cubierta. La curvatura del bao se denomina brusca.

BAUPRÉs: palo que sale de la proa en mayor o menor ángulo respecto al horizonte y al que se hacen firmes los estays del trinquete.

BoDEGA: espacio interior de las embarcaciones desde la cubierta, o cubierta más baja hasta la quilla.

BOMBA DE ACHIQUE: máquina destinada a elevar el agua de la sentina. Puede ser de cangilones, de noria o de pistones.

BORDA: canto superior del costado de un barco.

CABILlA: pieza de hierro o madera, de sección cuadrada o redonda con que se unen distintos elementos del casco a modo de clavo.

CALAdo: equidistancia vertical entre la quilla y la superficie del agua.

CARENA: parte sumergida del casco de un barco u obra viva.

CARGamento: conjunto de mercancías que transporta una embarcación.

CARLINGA: asiento en el que descansa la extremidad inferior de un palo o mecha del mástil, formado por una pieza proporcionada de madera con escopladura para engastar la coz del palo.

CAsco: cuerpo del barco sin arboladura, ni pertrechos, ni superestructuras.

CASTILlo: estructura situada por encima de la cubierta desde el trinquete hasta la proa.

CINTA: fila de tablones más gruesos que los restantes del forro, colocada de proa a popa a lo largo de los costados como refuerzo longitudinal.

CinTón: defensa de madera, dispuesta longitudinalmente en los costados del barco, para proteger y reforzar el casco en los atraques y maniobras de abarloamiento.

Clavisa: pieza de madera, de pequeño tamaño y forma cilíndrica o troncocónica, utilizada para unir las llaves a las tracas del forro. 
CODASTE: pieza resistente que tiene su pie en la quilla y que forma el extremo posterior del casco, cerrando la obra viva en la popa del barco.

ConTRAQUILLA: pieza que cubre toda la quilla por la parte interior de la embarcación.

Costado: cada uno de los lados del casco de un barco, desde la borda hasta la línea de flotación o el pantoque.

Coz: extremidad inferior de un palo.

CUADERNA: cada una de las piezas curvas, perpendiculares a la quilla, que forman el costillaje de la nave, compuesta por varenga, genol y ligazones.

CUBIERTA: estructura horizontal, en forma de piso, que se extiende totalmente de proa a popa y de banda a banda soportada por los baos.

EsCORA: inclinación de un barco de una a otra banda por efecto del viento, corrimiento del viento u otra causa.

Escotilla: abertura rectangular o cuadrada, en la cubierta para introducir y extraer carga y efectos de las bodegas del barco.

ESLORA: longitud de un barco de proa a popa.

ESPIGA: terminación afinada de una pieza; extremo de una pieza para entrar como macho en la cajera de otra.

ESTAY: cabo que sujeta la cabeza de un mástil al pie del más inmediato, para impedir que caiga hacia la popa.

ESTIBAR: colocar o distribuir, convenientemente y en su orden, todos los pesos del barco, de forma que quede en buenas condiciones para la navegación.

FORRO: conjunto de tablas que cubren el casco de un barco.

GENOL: en la cuaderna, pieza que une lateralmente a la varenga con la primera ligazón.

GOBIERNO: manejo del timón, para dirigir la embarcación a un rumbo determinado o hacerlo evolucionar para ejecutar una maniobra.

JARCIA: conjunto de aparejos y cabos de un barco.

LigAzón: cada uno de los maderos que se enlazan para componer las cuadernas.

MANGA: anchura de un barco.
MÁstIL: palo, mastelero.

MAYOR: nombre que se da a la vela principal del palo mayor.

MEDiA CUADERNA: ligazón que toca la quilla sin sobrepasarla.

MeSANA: palo de popa en las embarcaciones de dos o tres palos.

MoRTAJA: entalladura que sirve para alojar la lengüeta que une dos tracas.

MoTón: polea que sirve para cambiar de dirección los cabos.

OBRA VIVA: parte sumergida del casco.

PANA: cada una de las tablas levadizas, que forman el plan o piso de la embarcación.

PANTOQue: parte del forro o carena, que une la vertical de los costados con la horizontal del fondo del buque.

PERNO: clavo de hierro largo y de forma cilíndrica. Sirve para unir o afirmar diversas piezas.

PoPA: parte posterior de un barco.

PROA: parte delantera de una embarcación.

PunTAL: postes verticales que sujetan los baos; altura media en el centro de la eslora, desde la quilla a la cubierta.

QUILLA: columna vertebral de la embarcación.

REMO TIMÓN: remo de gran tamaño utilizado para gobernar las embarcaciones.

RoDA: pieza gruesa y curva que cierra la proa.

SENTINA: parte inferior del barco donde se depositan las aguas filtradas.

SOBREQUILLA: pieza paralela a la quilla y situada sobre las cuadernas y que sirve para unirlas y reforzar el casco longitudinalmente.

TRACA: hilada de tablas en los forros y cubiertas del barco.

TRINQUETE: palo más próximo a proa en las embarcaciones con más de uno.

VARENGA: pieza curva que se pone de babor a estribor sobre la quilla para formar la cuaderna. 